\title{
A Study \\ on \\ Electrostatics and Its Hazards
}

by

NIRMALYA BASU

(Master of Engineering in Electronics and Telecommunication Engineering)

Date of Birth: May 3, 1984

Email: nirmalya1basu@gmail.com

Mobile: +919007757186

Address: 162/B/185 Lake Gardens, Kolkata, West Bengal, India, PIN: 700045. 


\section{Contents}

$\begin{array}{ll}\text { 1. Introduction } & 1\end{array}$

2. Electrostatics in Liquids and Its Hazardous Implications $\quad 2$

2.1. The Phenomenon of Flow Electrification 2

2.2. Hazards in the Industry $\quad 5$

2.2.1. Metallic Fuel-handling Systems 6

2.2.2. Non-metallic Fuel-handling Systems $\quad 6$

2.3. Liquid Charging Due to fragmentation and Hazards Arising Thereof 8

2.3.1. The Charging Phenomenon 8

2.3.2. Industrial Hazards $\quad 8$

2.3.3. Remedial Measures

2.4. Standards on Recommended Practices 11

‥ Electrostatics in Solids and Its Hazardous Implications 12

3.1. Phenomenon of Contact Charging or Tribocharging of Solids 12

3.1.1. Phenomenon of Charging of Two Metal Objects Brought in Contact

with Each Other $\quad 12$

3.1.2. Phenomenon of Contact Charging of Solids when Insulators

$\begin{array}{ll}\text { are Involved } & 14\end{array}$

3.1.3. Charging of Two Identical Materials Brought in Contact with

$\begin{array}{ll}\text { Each Other } & 18\end{array}$

3.1.4. Contact Charging of Granules

3.2. Hazards Caused in the Industry Due to Charging of Solids 21

3.2.1. Electrostatic Hazards in Particulate Processes 22

3.2.2. Electrostatic Hazards in the Semiconductor Industry 25 
$\begin{array}{ll}\text { 4.1. Combustion } & 27\end{array}$

4.2. Ignition: Piloted Ignition and Autoignition $\quad 27$

4.3. Limits of Flammability 28

4.4. Fire Point 29

4.5. Principles of Fire $\quad 30$

5. Gaps in Knowledge and Ways of Bridging Those 31

5.1. Knowledge Gap in Electrostatics of Liquids and Way of Bridging It 31

5.2. Knowledge Gaps in Electrostatics of Solids and Ways of Bridging Those 32

5.2.1. Regarding the Contact Charging of Insulators 32

5.2.2. Regarding the Surface Potential Decay of Polymers 33

5.2.3. Regarding the Tribocharging of Wood 36

$\begin{array}{ll}\text { References } & 38\end{array}$ 


\section{Chapter 1}

\section{Introduction}

Electrostatics is one of the oldest branches of physics. It is so old and its manifestations so commonplace that A. D. Moore writes in his book ('Electrostatics: Exploring, Controlling and Using Static Electricity', Laplacian Press, $2^{\text {nd }}$ edition, 1997), "Did the caveman have a cat? If so, he was our first electrical scientist. As he stroked his pet in a dry cave, the fur would get "charged". It would become rumpled and ridgy; and in the dark, there would be tiny sparks to be seen.’Despite its antiquity, it is a vibrant field of research even today.

What is electrostatics? The standard definition given by IEEE was "the branch of science that treats of the electric phenomena associated with electric charges at rest in the frame of reference" (vide P. Molinié, IEEE Transactions on Dielectrics and Electrical Insulation, Vol. 18, No. 5, October 2011). It was too restrictive to allow for practical applications as no such application could be possible without having charged particles set in motion. This led Moore to create a new organisation, the Electrostatics Society of America, which adopted the following definition (videhttp://www.electrostatics.org/electrostatics.html): "Electrostatics is the class of phenomena recognized by the presence of electrical charges, either stationary or moving, and the interaction of these charges, this interaction being solely by reason of the charges and their positions and not by reason of their motion."Put in terms of electric circuits, this definition implies that a process is said to be governed by electrostatics if the ratio of voltage to current in that process is very high. There is a general misconception that high voltages are necessarily a part of electrostatic processes. This is not true as the electric field, which is the gradient of voltage, depends not only on the voltage, but also on the size, shape and separation between the electrodes. To cite examples, while certain electrostatic painting processes, which work for separation distances of tens of centimetres, require voltages ranging from 50 to $100 \mathrm{kV}$, laser printers, which involve distances of tens of microns, produce similar effects with only tens of volts (vide G. S. P. Castle, IEEE Industry Applications Magazine, July/August 2010).

Electrostatic forces have been harnessed and put to our use in various ways, the photocopying machine, the laser printer, the electrostatic painting and powder coating processes and the electrostatic precipitator being a few of its examples. However, instances in which it has gone out of control presenting us with fatal hazards are not wanting. These have occurred mostly in the petroleum and chemical industries, and also in the particulate process industries. In what follows, we shall talk about the mechanisms by which solids and liquids get charged by contact and also the hazardous implications of such charging. We shall first consider the case of liquids and then move on to solids. We shall also take a look at the principles of fire. Finally, we shall identify the gaps existing in the present knowledge of the subject, as also the ways that might help in bridging them. 


\section{Chapter 2}

\section{Electrostatics in Liquids and Its Hazardous Implications}

In Germany, between 1992 and 1995, more than 30 incidents had been reported where ignitions of gasoline/air-mixtures had occurred during car refuelling. Upon investigation, it was felt that electrostatic charging was most likely to have been responsible for most of them [1].

On $17^{\text {th }}$ July, 2007, an explosion and fire were reported to have occurred at the Barton Solvents Wichita facility in Valley Centre, Kansas at about 9 A.M. The incident left the tank firm completely destroyed. Eleven residents and one fire-fighter had to be given medical treatment. This incident was investigated by the U.S. Chemical Safety and Hazard Investigation Board (CSB). It was concluded that the initial explosion took place inside a vertical aboveground storage tank while it was being filled with Varnish Makers' and Painters' (VM\&P) naphtha, which is a National Fire Protection Association (NFPA) Class IB flammable liquid that can produce ignitable vapour-air mixtures inside tanks and is also capable of accumulating dangerous levels of static charge due to its low electrical conductivity [2].

In 2008, a flash fire was reported which occurred at the production site of a company in the process industry while filling $200 \mathrm{l}$. drums with isopropyl acetate [3]. This too was traced to electrostatic causes.

In fact, the root cause of all the incidents stated above is that the liquid fuels involved have the propensity to accumulate high levels of static electricity while flowing through a pipe, or in general, while flowing past a solid surface. Many other liquids have this property. The phenomenon is also called "flow electrification".

Many liquids also get charged when, on being sprayed through a small nozzle or upon impact with a solid surface, they are broken into small droplets that form a mist.

In what follows, we shall look at these important phenomena by which liquids get charged and their hazardous implications in the industry. We shall first have a glimpse of the flow electrification phenomenon.

\subsection{The Phenomenon of Flow Electrification}

G. Quincke discovered in 1859 that if a liquid is forced through a capillary tube or a porous material, such as, a diaphragm of clay, a difference of electric potential is set up between the two sides. He tried to explain his observation by postulating that electrically charged layers of 
opposite sign existed at the boundary between the liquid and the material of the capillary or the diaphragm as shown below (fig. 2.1).

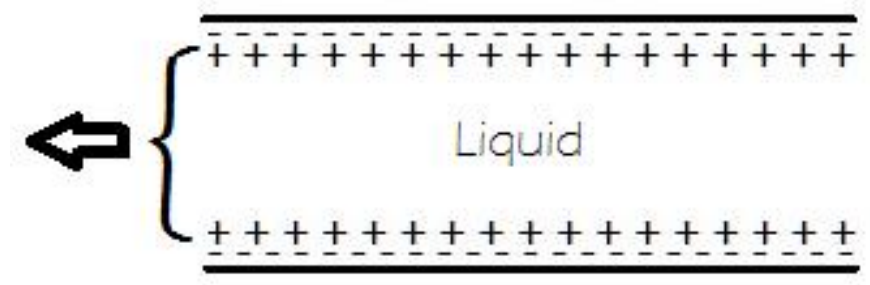

Fig. 2.1 Electric Double Layer in the Capillary as Conceived by G. Quincke and Later Developed by H. von Helmholtz

This combination of electrically charged layers is also popularly known as the "electric double layer". He stated that the "inner" layer adjacent to the capillary wall remains firmly adhered to it. But, the "outer" layer, being in the body of the mobile liquid, moves with it $[4,5]$. This leads to a separation of positive and negative charges and results in the observed difference of potential between the two sides of the capillary. The resulting current is known as the "streaming current" and the potential difference that develops between the two sides of the capillary is referred to as the "streaming potential".

In order to be able to treat the phenomenon mathematically, Helmholtz assumed that the electric double layer is equivalent to a parallel-plate capacitor with the plates $d \mathrm{~cm}$. apart, each carrying a charge $\sigma$ per sq. $\mathrm{cm}$. $[4,5]$. The difference of potential between the plates is assumed to be $\zeta$. This potential, $\zeta$, is known as the "electrokinetic potential". The term "zeta-potential" is also often used for it because of the symbol conventionally employed for its representation. It is a measurable quantity, the value of which may be obtained from electroosmotic experiments. Electroosmosis is the opposite of the streaming potential phenomenon and here, a liquid is forced through a capillary or a porous diaphragm by applying a potential difference across its two sides. If $\varepsilon$ be the dielectric constant of the liquid, and hence, of the medium between the hypothetical plates, then

$$
\zeta=4 \pi \sigma d / \varepsilon
$$

Assuming the liquid to be flowing through the capillary in a laminar fashion, its velocity is given by

$$
u=P\left(r^{2}-x^{2}\right) / 4 \eta l \quad \ldots(2)
$$

where $P$ is the hydrostatic pressure difference between the two sides of the capillary which results in the flow of the liquid, $r$ is the inner radius of the capillary, $x$ is the distance from the centre of the tube, $\eta$ is the coefficient of viscosity of the liquid and $l$ is the length of the capillary tube. 
Hence, the moving part of the double layer, being at a distance of $(r-d)$ from the centre, must move with a velocity $u_{d}$ given by

$$
u_{d}=r d P / 2 \eta l
$$

the very small quantity $d^{2}$ being neglected in comparison with $2 r d$.

The streaming current $I$ produced is given by

$$
I=2 \pi \sigma u_{d}=\pi r^{2} \sigma d P / \eta l
$$

If $\kappa$ be the specific conductance of the liquid, then its conductance is equal to $\left(\pi r^{2} \kappa / l\right)$. Now, if $S$ be the streaming potential produced, we have, by Ohm's law,

$$
\begin{aligned}
S & =I l / \pi r^{2} \kappa \\
& =\sigma d P / \eta \kappa
\end{aligned}
$$

Substituting the value of $\sigma d$ in (4) and (5) from (1), we have

$$
I=\zeta \varepsilon r^{2} P / 4 \eta l
$$

and

$$
S=\zeta \varepsilon \mathrm{P} / 4 \pi \eta \kappa \ldots(7)
$$

We have used the C.G.S. system of units in the above analysis for ease of mathematical manipulations.

The beauty of this theory is that it explains the phenomenon of flow electrification in a simple manner. However, its validity is restricted only to aqueous solutions flowing in a laminar fashion where fields are small except in a very thin layer near the boundary. In hydrocarbons, the liquid part of the double-layer is smeared exponentially over a comparatively larger range. Moreover, in case of turbulent flow, the outer part of the layer is affected by turbulent mixing and voltage differences occur throughout the liquid. So, the concept of zeta potential loses its validity in such cases. This theory has been updated and modified by a number of researchers like Guoy, Chapman, Debye, Huckel, Stern, to name but a few. However, none of the theories is considered complete and people are still working on trying to formulate a cogent theory for this phenomenon. But in spite of all the differences that exist among the theorists, all of them agree on the fact that the streaming current must increase with increase in either the flow velocity or the tube diameter or both. The increase associated with tube diameter is due to the resulting increase in total interface area. This explains why incorporation of filters in the path of liquid flow results in the liquid getting much more highly charged than occurring otherwise. This is because filters result in enhancement of the flow velocity and also the contact area [6].

Here, one thing needs to be borne in mind. The charging, as discussed above, occurs mostly in liquids that have their conductivities above $10^{-13} \mathrm{~S} / \mathrm{m}$. The reason for this is that, 
otherwise, enough ions are not produced in the liquid to form the electric double layer. The charging reduces below this level of conductivity. However, in highly viscous liquids, it may be high even for conductivities below $10^{-13} \mathrm{~S} / \mathrm{m}$. The charging is, however, observable only in those liquids that have their conductivities below $10^{-7} \mathrm{~S} / \mathrm{m}$. This is because in case of highly conductive liquids, the charges in the liquid get relaxed to the walls of the tube too fast to be able to produce any detectable streaming current [7]. We shall now proceed to see the different ways in which this phenomenon leads to hazards in the industry.

\subsection{Hazards in the Industry}

Let us consider the example of a simple tank-filling facility as shown in fig. 2.2.

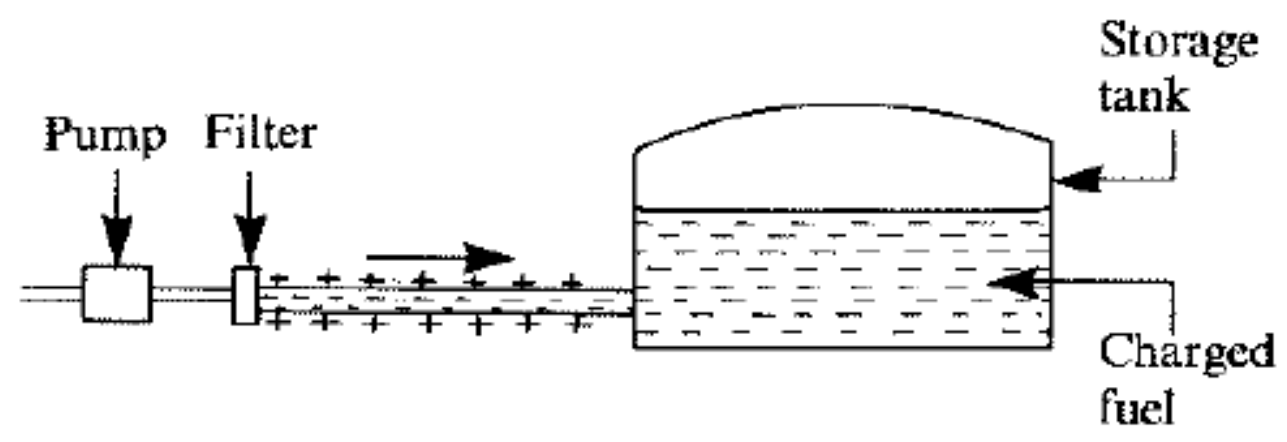

Fig. 2.2 Schematic of a Simple Tank-filling Facility (reproduced from [6])

Let us assume here that the positive charge appears on surface of the delivery pipe-work, which is assumed to be metallic, and the negative charge occurs in the liquid fuel. If the pipe-work is grounded, the positive charge will disappear to ground; but the negative charge will flow along with liquid and get accumulated in the storage tank. If the fuel has very low conductivity, say, between $10^{-11} \mathrm{~S} / \mathrm{m}$. and $10^{-13} \mathrm{~S} / \mathrm{m}$., which is typical for hydrocarbons, the charge within the mass of the liquid cannot easily flow to the tank wall and from there, to ground [6]. This results in a continual build-up of charge within the tank, thus, leading to the development of high electric fields and potentials. This often results in either an incendive brush discharge between the charged liquid surface and a nearby earthed metal conductor or, if the tank is unearthed, an incendive spark discharge between the body of the metal tank, which acquires charges by induction, and a nearby metal object at a different potential. If the tank is unearthed and a spark discharge occurs, this may result in an ignition hazard if the energy of the discharge is greater than or equal to the minimum ignition energy, often referred to as the MIE, of the fuel-vapour/air mixture in the ullage space of the tank. The minimum ignition energy of a fuel-vapour/air mixture is the minimum energy that must be supplied to it by a spark to be able to ignite it. A brush discharge has lower spatial energy density compared to a spark discharge of the same energy, and hence, it is less effective than a spark discharge in causing ignitions. So, for brush discharges, the ignition criterion is specified in terms of the charge transferred in a discharge, and not in terms of the energy of the discharge and the MIE of the fuel. In the above scenario, if 
a brush discharge occurs, it is likely to result in an ignition hazard if the charge transferred is greater than $60 \mathrm{nC}$ (standard for typical hydrocarbon fuels).

We need to understand, here, that the situations are quite different in fuel-handling systems that are made of metal and those that are fabricated of non-metal. In metal systems, the dissipation of charge of one sign (that developing on the pipe-work), at least, can be easily accomplished grounding the complete facility. But, such is not the case for systems made of insulating materials. We shall, therefore, take up the subjects of metallic and non-metallic systems separately, and try to understand the various things that need to be taken care of in both cases.

\subsubsection{Metallic Fuel-handling Systems}

As can be easily understood from the above discussion, the only thing that remains to be done in metallic systems is to find ways to ensure that the charge developing in the bulk of the liquid easily gets dissipated. This can be done, quite effectively, by adding to the fuel an anti-static additive, such as, Octel Stadis 425 , Octel Stadis 450 etc. Addition of such additives helps to increase the conductivity of the bulk fuel, making it possible for the charge to dissipate rapidly to the grounded structure of the storage tank. However, when using such additives, what needs to be ensured is that their addition does not hamper the performance of the fuel in normal use.

\subsubsection{Non-metallic Fuel-handling Systems}

As discussed earlier, in fuel-handling systems where the delivery pipes are fabricated of insulating material, the charge appearing on the pipe-work and the related hardware cannot be dissipated by simply connecting the system to ground. Hence, in this case, dissipation of charge of both signs depends purely on the anti-static additive in the liquid. Here, what needs to be remembered is that the anti-static additive merely increases the conductivity of the liquid; it does not suppress the charging process. Thus, in case of insulating pipe-work, the charge is still created, and in spite of the liquid being relatively more conductive, this charge does not find a direct route for easy dissipation to ground. Extreme care is needed when using insulating delivery pipes in fuel-handling systems, and use of above-the-ground insulating delivery pipes as shown in the schematic (fig. 2.3) below is forbidden by most guidelines, the reasons for which are explained in the following. 


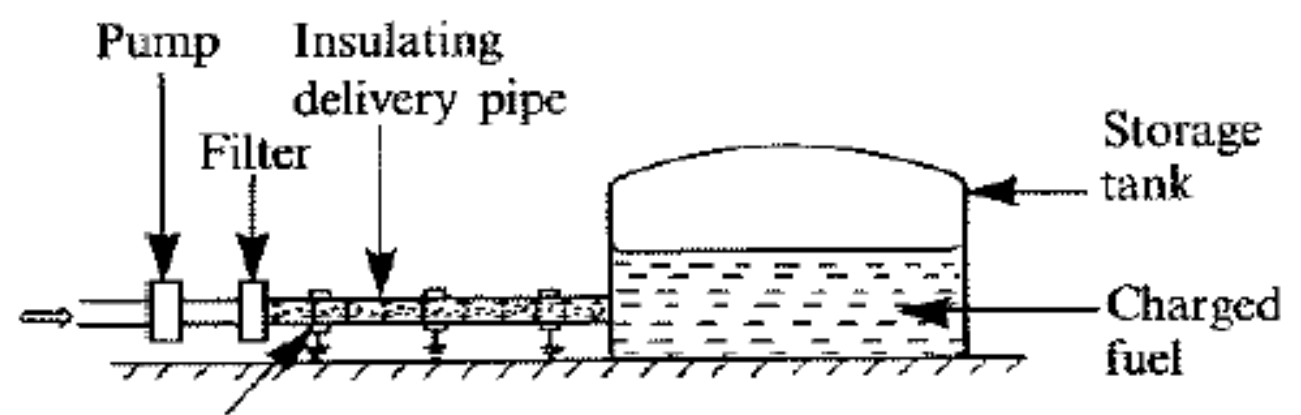

\section{Earthed metal support}

Fig. 2.3 Tank Storage Pumping Facility Using Insulating Pipe-work (reproduced from [6])

In the insulating pipe section, there is no direct route by which the charge on the inner wall of the pipe can dissipate to ground. The charge in the fuel may, however, find its way to ground through the fuel (plus antistatic additive) and the tank wall, provided the tank is made of metal and it is earthed. It is, therefore, obvious that dangerous levels of charge can easily accumulate on the inner wall of the pipe. The situation is made even worse if the system makes use of metal clamps for support as shown in fig. 2.3 [6]. This is because the negative charge in the liquid in the vicinity of the earthed clamp will induce an equal and opposite charge on the clamp. This will increase the electric field in that region and will cause more negative charges in the liquid to accumulate near the clamp. This will lead to the charge distribution depicted in fig. 2.4 .

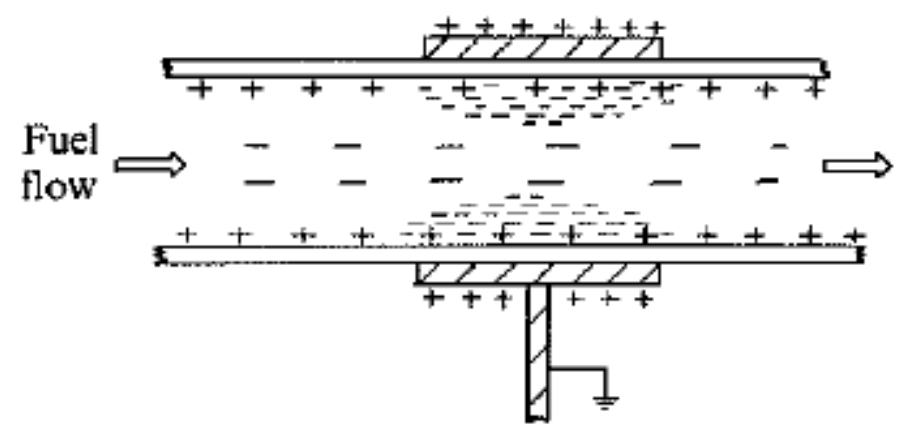

Fig. 2.4 Cross-section Showing Possible Distribution of Charge in the Vicinity of a Metal Ring around an Insulating Pipe (reproduced from [6])

Thus, a gradual build-up of charge as well as of the electric field across the pipe wall will take place. This may turn out to be hazardous as it can lead to breakdown of the pipe wall resulting in puncturing and loss of liquid into the surroundings. Moreover, if the liquid is inflammable, a secondary spark may result in an ignition hazard. It may even happen that the leak in the wall acts as an efficient charge source, especially if the liquid comes out of it in the form of an 
atomized jet. It needs to be borne in mind that the hazards associated with metal clamps may also be present at the points where the insulating pipe in connected to grounded metal pipes or tanks. It needs to be borne in mind that removing metal clamps does not remove the possibility of occurrence of hazards as very high surface voltages ( > $100 \mathrm{kV}$ ) may be produced.

\subsection{Liquid Charging Due to Fragmentation and Hazards Arising Thereof}

\subsubsection{The Charging Phenomenon}

One of the earliest observations of charging of droplets was observed by Lord Armstrong in 1840. He observed in a locomotive at Sedgehill, England that the wet steam, blowing out of a small nozzle or a crack on it, was charged [8]. In 1892, Lenard observed that the fine spray that was produced by impact of water drops on water surfaces contained high negative charge. If the drops were made to impinge on a zinc plate, the charging of the mist was greater. In fact, when the zinc plate was ventilated by a light current of air, the charging was found to be two to three times greater [8].

In fact, the fragmentation of many liquids by impact or spraying results in the generated mist acquiring some charge. It appears today that such charging is effected by a shearing of the double layer at the liquid interface [6].

\subsubsection{Industrial Hazards}

This effect has been responsible for many ignition hazards that have occurred during cleaning of tanks containing incendive atmosphere. A well-known incident of this kind is the supertanker explosion that occurred in December, 1969. Severe damage occurred in the empty cargo tanks of three supertankers while they were being washed. The tanks were being washed by using highpressure water cannons that were capable of discharging $180 \mathrm{~m}^{3} / \mathrm{h}$ of sea water at flow velocities up to $40 \mathrm{~m} / \mathrm{s}[9]$.

Operations of this kind produce a dense aerosol within the tank due to fragmentation of water jets at the cleaning nozzle as well as at the point of impact on the tank wall. Generally, aerosols of this kind consist of two kinds of droplets - (a) the comparatively large and heavy drops that fall quickly to the floor of the tank and (b) the extremely fine droplets that remain suspended within the volume of the tank for long durations, sometimes, even for few hours [6]. As a result, a cloud of unipolar charge gradually develops within the volume of the tank since the coarse drops and the fine aerosol droplets have charges of opposite sign. It is clear that existence of such charged cloud within the tank is undesirable in cases where the tank atmosphere is incendive. There are three ways in which such a charged cloud can give rise to a discharge - (A) a falling drop giving rise to a corona type of discharge, (B) a falling slug resulting in a spark and 
(C) an earthed projection inside the tank giving rise to a brush discharge $[6,10]$. These mechanisms are discussed below.

A. Corona Discharge from a Falling Drop: When a drop of liquid leaves an object under the action of gravity, its head gradually gets drawn into a sharp conical point as shown in fig. 2.5.

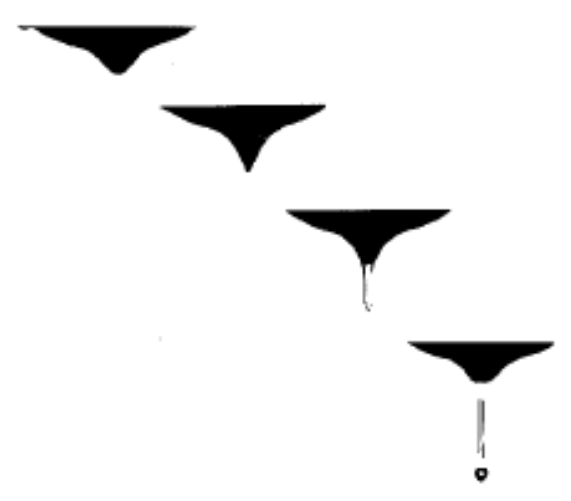

Fig. 2.5 Elongation of a Water Drop When Falling under Gravity (reproduced from [6])

If an electric field is present there, and on top of that, the liquid is conducting, then a corona type of discharge often occurs due to intensification of the electric field at the sharp point on the head of the drop. But such discharges normally have energies less than $0.01 \mathrm{~mJ}$ which is insufficient to ignite vapours associated with petroleum products [6]. However, such discharges are not desirable in cases where the atmosphere requires energies of around $0.01 \mathrm{~mJ}$ to ignite. If the incendivity of the atmosphere is not known, then, the atmosphere should be inerted, i.e., filled with an inert gas so that the quantity of oxygen in that atmosphere is reduced [6].

B. Spark from a Falling Slug: A spark can be caused by both a charged and an uncharged slug of wash water, emulsion or waxy crude sediment. How it occurs is depicted in the following figure (fig. 2.6). 


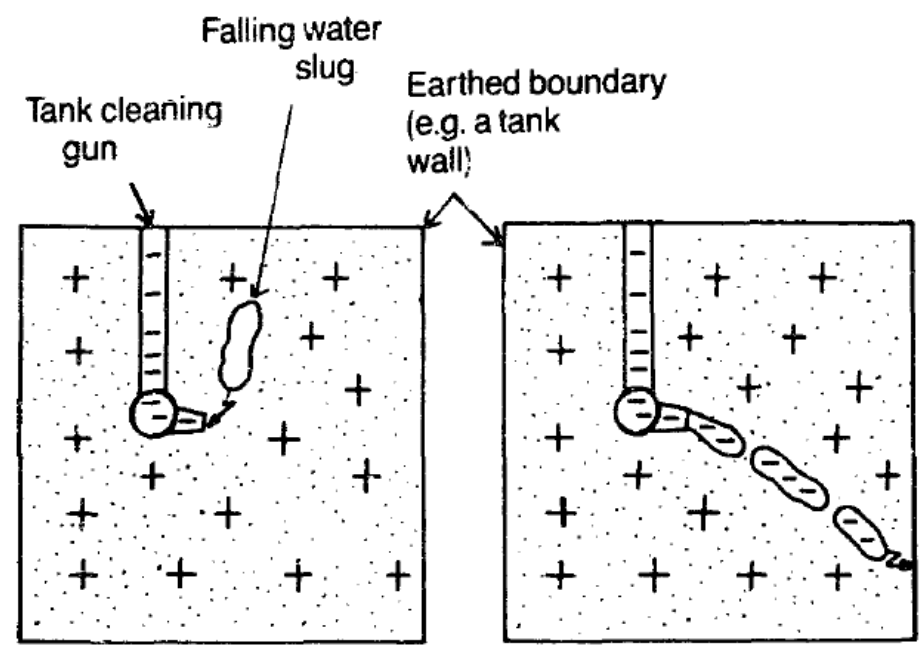
(a) Spark from an unchar ged isolated Water Slug to on earthed projection
(b) Spark from a charged isolated Water Slug to a tank wall

Fig. 2.6 Spark Occurring from a Falling Slug ('+' denotes positive charge on the mist; '-' denotes induced negative charges) (reproduced from [10])

C. Brush Discharge from an Earthed Projection inside the Tank: The presence of an earthed projection inside the tank, such as, the head of a tank cleaning gun, can give rise to a brush discharge in the presence of a charged mist. How this happens, is illustrated in fig. 2.7.

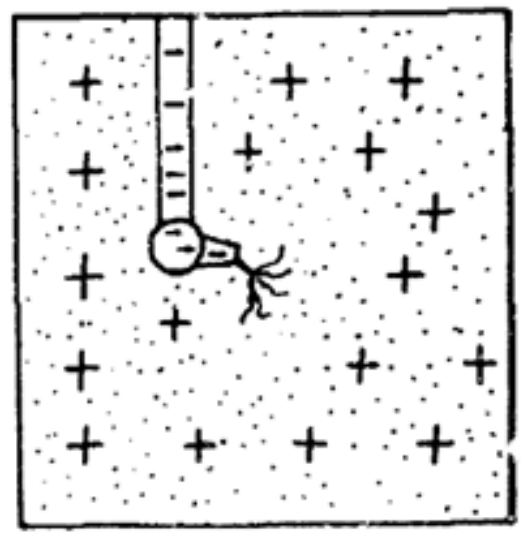

\section{Brush discharge from an earthed projection near the tank centre}

Fig. 2.7 Brush Discharge from an Earthed Projection inside the Tank ('+' denotes positive charge on the mist; '-' denotes induced negative charges) (reproduced from [10])

The spark and the brush discharges illustrated in (B) and (C) above might have energies that can cause ignition of vapours from petroleum products [6]. 


\subsubsection{Remedial Measures [6]}

It has been suggested that a discharge may be prevented by chemically doping the wash-water in such a way that the net charge in the aerosol is zero, thus, getting rid of the electric field. However, since the doping levels are extremely critical and the volume of liquid normally handled is large, difficulties are envisaged in its implementation in normal conditions. A more realistic option is to neutralize the charge in the aerosol by using corona points or wires strung across the tank. But this is not considered suitable for highly incendive atmospheres since it depends on corona discharges. Radioactive dischargers are relatively safe charge neutralizers and are widely used. They are especially suitable for situations where the quantity of charge is relatively small. Another option is to make the atmosphere either too rich or too lean for ignition to take place. Inerting the tank atmosphere appears to be the safest and the easiest way to prevent an ignition. It is recommended that any enclosure having an incendive atmosphere be fitted with a gas-mixture device which can be adapted for automatic atmosphere control and necessary alarming.

\subsection{Standards on Recommended Practices}

From the above discussion, we find how easily liquids can get charged in processes that are almost regularly carried out in everyday life, such as, making them flow through a pipe, spraying etc. We also find how dangerous such charging can turn out to be when handling fuels. Hence, in processes where handling liquid fuels is inevitable, such as, those involved in the petroleum and chemical industries, every precaution needs to be taken to guard against such electrostatic hazards. IEC/TS 60079-32-1 [12] and IEC 60079-32-2 [12] provides detailed recommendations for preventing such hazards. However, every situation has its own individual feature, and hence, there may be cases which are not directly covered by such standards. Such situations need to be taken care of on a case-to-case basis. To be able make the ignition-hazard prevention strategies effective, one needs to have a clear understanding on the principles of fire. These are covered in Chapter 4 of this report and, in a greater detail, in [11]. 


\section{Chapter 3}

\section{Electrostatics in Solids and Its Hazardous Implications}

\subsection{Phenomenon of Contact Charging or Tribocharging of Solids}

It is a most astounding fact that the phenomenon, that of charging of solids by contact, which is known to have been first observed by Thales of Miletus, which has been put to use in numerous of our applications ranging from the photocopying machine to the electrostatic precipitator, which again has posed us with fatal hazards in the industry, is so little understood even today. However, constant struggle towards achieving this end has left us with some empirical facts as well as with some rather deeper understanding in certain cases, of the phenomenon for both metals and insulators. Charging of two metal objects brought to contact seems to be rather straightforward, and therefore, we shall begin our study with that.

\subsubsection{Phenomenon of Charging of Two Metal Objects Brought In Contact with Each Other}

To be able to understand this phenomenon, we first need to develop some idea on the free electron model of a metal [13]. An electron in any solid is under the influence of the field due to all nuclei and all other electrons. Hence, the potential energy of such an electron may be expected to be periodic because of the periodicity of the lattice. However, in developing the electron theory for metals, Sommerfeld assumed that the "free" electrons, i.e., the valence electrons of the atoms, which are responsible for the conductivity of a metal, have a potential energy which is constant, i.e., independent of position, inside the metal. As electrons are not found to be emitted from metals at room temperature, it may be reasonable to suggest that an electron at rest inside a metal has a potential energy which is lower than that possessed by an electron at rest outside the metal. It is generally assumed that an electron suffers an abrupt change in its potential energy as it crosses the metal-vacuum boundary. This leads us to a physical model which depicts the interior of a metal as a potential-energy box as shown in fig. 3.1 below.

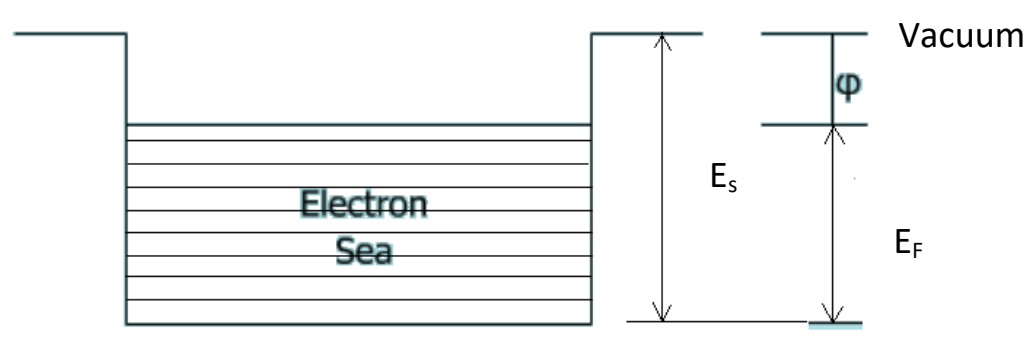

Fig. 3.1 The Sommerfeld Model for Electrons in a Metal 
In the above figure (fig. 3.1), $\mathrm{E}_{\mathrm{s}}$ is the difference between the energy of an electron at rest in vacuum and that of an electron at rest inside the metal. $E_{F}$ is the Fermi level, which denotes the highest energy level that is filled with electrons at $T=0 \mathrm{~K} . \varphi\left(=\mathrm{E}_{\mathrm{s}}-\mathrm{E}_{\mathrm{F}}\right)$ is the work function of the metal, and it denotes the minimum energy that must be supplied to an electron inside a metal to get it released.

Now, for visualizing the charging phenomenon involved in a metal-metal contact $[13,14$, 15], let us consider two different metals having work functions $\varphi_{1}$ and $\varphi_{2}$ at absolute zero temperature. Compared to the "vacuum level", the energy levels of the electrons in the two metals may be represented as shown below in fig. 3.2.

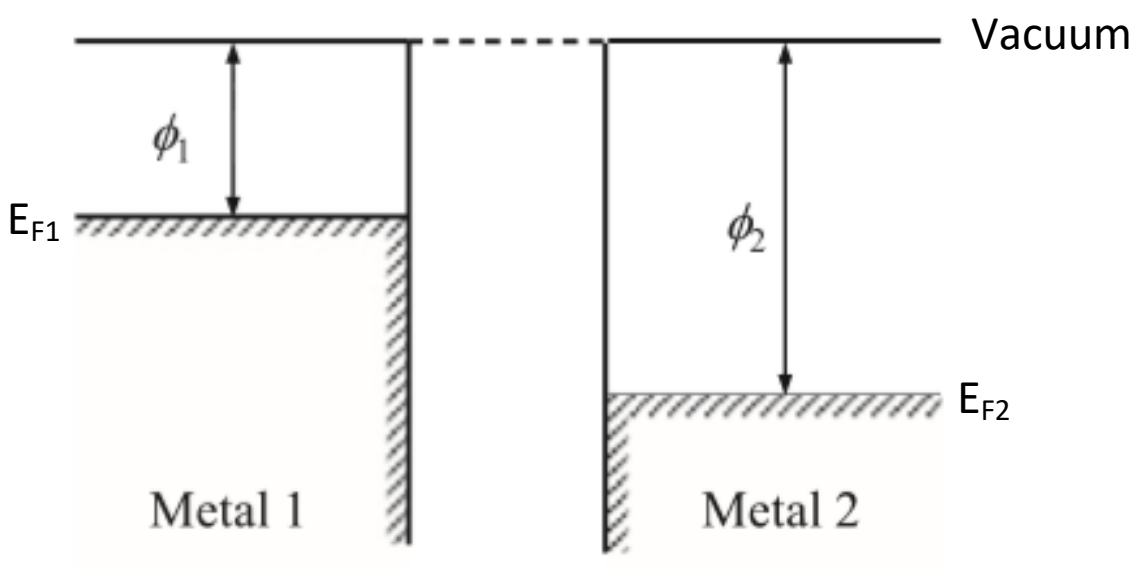

Fig. 3.2 Energy Levels of Electrons in the Two Metals Compared to a Common Vacuum Level before Contact (Reproduced from [15])

Now, let us suppose that the two metal objects are brought in contact with each other. In this situation, the two metals are, in strict terms, separated, the separation distance being comparable to interatomic distances. If we assume that $\varphi_{1}<\varphi_{2}$ as shown in fig. 3.2, the energy can be lowered by transferring an electron from metal 1 to metal 2. Evidently, the situation depicted in fig. 3.2 is unstable. Hence, a certain number of electrons must move from metal 1 to metal 2 by tunneling through the potential energy barrier, or, for temperature above absolute zero, by thermionic emission. As a result, the surfaces of the metals 1 and 2 will acquire positive and negative charges, respectively. As the number of electrons transferred from metal 1 to metal 2 increases, the more difficult it becomes for the other electrons in metal 1 to move to metal 2. Finally, an equilibrium will established in which the Fermi levels will coincide, resulting in a difference of potential between the two metal surfaces. This situation is depicted in the following figure (fig. $3.3)$. 


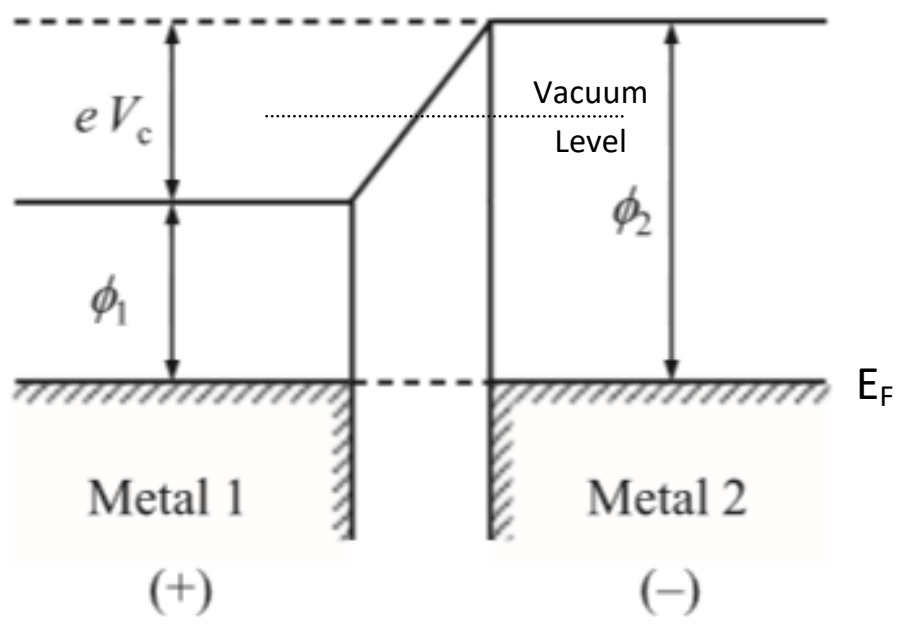

Fig. 3.3 The Equilibrium Situation Showing the Contact Potential Difference $\left(\varphi_{1}-\varphi_{2}\right)$ when the Two Metals are Brought in Contact with Each Other (Partially Reproduced from [15])

Obviously, the potential difference between the two metal surfaces is given by

$$
e V=\varphi_{1}-\varphi_{2} \quad \ldots(3.1)[13]
$$

It may be noted that $V$ is determined only by the work functions of the two metals in contact, and is independent of the depths of the respective potential-energy wells.

Experimental proof of this charging mechanism for metals was first given by Harper [16]. He demonstrated that at least one of the reasons of charging of two metal objects when they are brought in contact with each other is the contact potential difference between them. In his experiments, he used steel spheres that were electroplated with the test metals. He first demonstrated that for a particular pair of metal surfaces, the amount of charge separated on contact was always the same. Now, it is evident from the preceding discussion that the contact potential difference between two pairs of metal surfaces, say $\mathrm{A}$ and $\mathrm{B}$, and $\mathrm{B}$ and $\mathrm{C}$, are additive. Hence, if the charges generated on the metal surfaces were due to the contact potential differences between the metals, then these charges, too, had to be additive in nature. Harper found that to be so. He also calculated approximately the amount of charge generated in terms of the contact potential difference, and he found his results to be consistent with experiment.

\subsubsection{Phenomenon of Contact Charging of Solids When Insulators are Involved}

Much less understood is the phenomenon of contact charging of two solids when one or each of the solids involved is an insulator. One of the earliest attempts to study this phenomenon consisted of ordering of materials (both metals and insulators) according to the direction in which they transferred charge when one of them was brought in contact with another. This is the 
well-known 'triboelectric series' [17]. An example of this series is shown in the following figure (fig. 3.4).

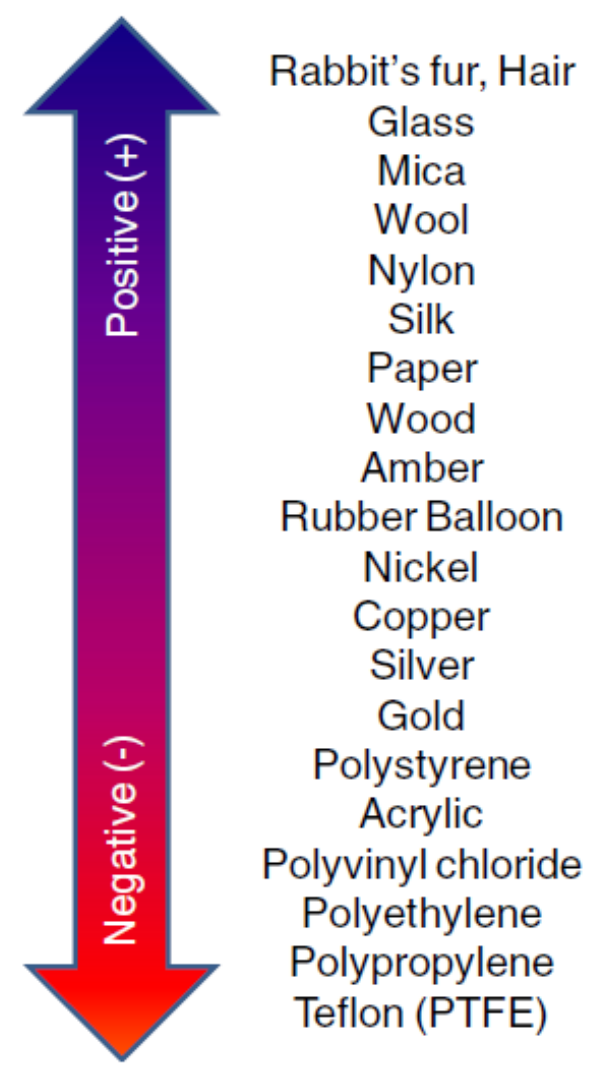

Fig. 3.4 Example of a Triboelectric Series (Reproduced from [17])

When the two surfaces of different materials in the triboelectric series are contacted, the surface made of the material that lies closer to the "Positive (+)" end of the series charges positively, and that made of the other material charges positively. For example, as shown in fig. 3.4, between silk and amber, silk lies more towards the "positive" end of the series than amber. Hence, when silk is rubbed with amber, silk acquires a positive charge, and amber, a negative charge. However, it has been observed in certain cases that different experiments lead to different orderings of materials. Variations in the environment, measurement techniques, and also small differences in the material are thought to be responsible for this variation.

People have also endeavoured to obtain a deeper understanding of the charging behaviour of insulators by trying to explain it using some of its intrinsic properties. Such attempts have led to the proposition of a few mechanisms which we shall now discuss.

The Electron Transfer Mechanism [17, 18]: For an insulator, the energy band structure of electrons is as follows. It consists of a filled valence band and an unfilled conduction band. The gap between these two bands is much larger than the thermal energy available, so that it not generally possible for an electron to move from the valence band to the conduction band. Hence, 
when two materials, one or both of which are insulators, are brought in contact with each other, it does not seem that transfer of electrons to the insulator is possible. This is because the valence states, being filled, lack room for further electrons, and the conduction states, being at a much higher energy level, cannot be reached by electrons, and hence, cannot be utilized for electron transfer. However, this description of an insulator is rather idealized, which is far from the reality in most cases.

Actually, most insulators contain in their band gaps, defect or "trap" states that are partially occupied by electrons. It is these electrons that are responsible for the finite conductivity, however small that may be, possessed by insulators. It is proposed that contact charging of insulators is made possible by transfer of these electrons, as shown schematically in the following figure (fig. 3.5).

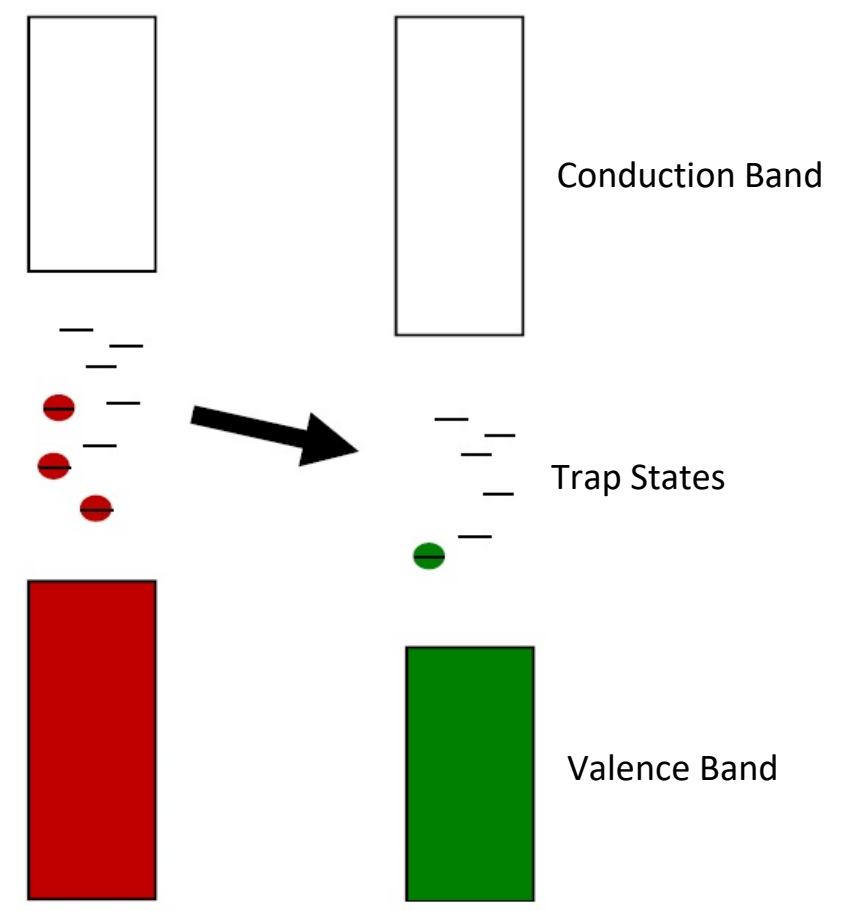

Fig. 3.5 Electron Transfer Model for Contact Charging of Insulators (Reproduced from [17])

The Ion Transfer Mechanism [17, 18]: This model has been put forth to explain contact charging mechanism for those insulating materials which contain mobile ions. These materials have on their surface, strongly bound positive or negative ions balanced by loosely bound ions of the opposite polarity. When brought in contact with another surface, the loosely bound ions could be transferred to this surface, leaving their parent surface with a net charge of the polarity of the strongly bound ions.

This model is also considered to be capable of explaining contact charging for materials that inherently lack mobile ions. In this case, transfer of ions present in water layers naturally occurring on the material's surfaces is considered to be responsible for contact charging. One 
mechanism based on this model states that adsorbed hydroxide ions are redistributed between the two surfaces in contact, thus causing the surfaces to be charged. This is schematically depicted in fig. 3.6 below.
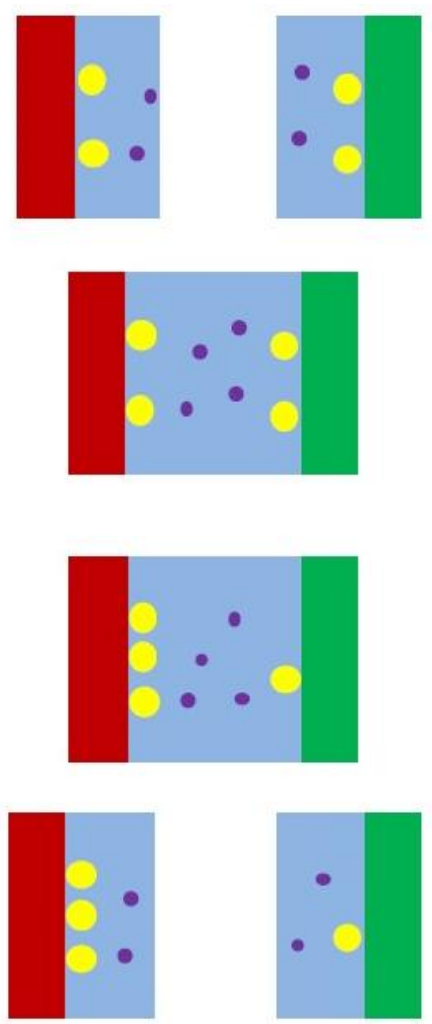

Fig. 3.6 The Ion Transfer Model, in Which Charge Transfer is Due To Redistribution of Ions in Adsorbed Water Layers on the Material Surface (Yellow Circles $\equiv$ Bound Ions; Purple Dots $\equiv$ Mobile Ions) (Reproduced from [17])

The Material Transfer Mechanism [17, 18]: This model states that minute patches of materials, roughly of the order of nanometres to micrometres in size, are transferred between two surfaces when they are brought to contact. It is quite likely that these patches carry charge as material transfer must be accompanied by breaking of bonds. This mechanism is schematically depicted in the following figure (fig. 3.7). 

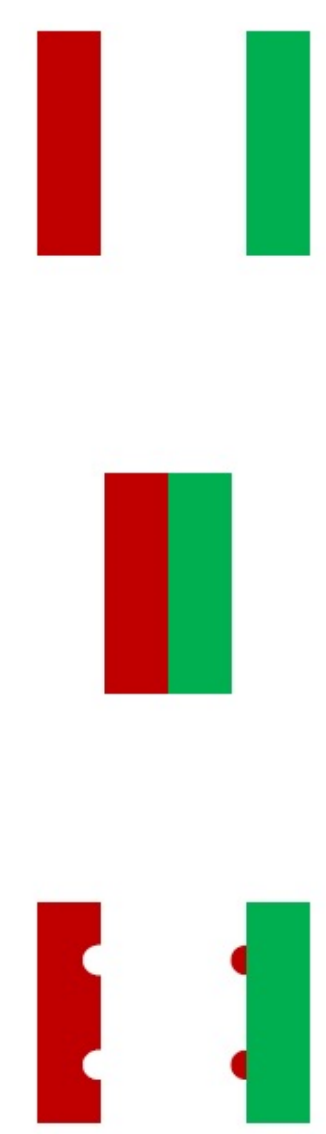

Fig. 3.7 The Material Transfer Model (Reproduced from [17])

The Mechanochemical Mechanism [17]: There is a class of chemical reactions which occur due to scission of bonds by mechanical stress. This is known as 'mechanochemistry'. Any contact between two material surfaces generates a certain amount of stress due to the cohesive force acting between them. Of course, vigorous rubbing causes the stress to be much greater. The stress may be magnified over localized regions due to roughness of the surface causing bonds to break. This produces either a pair of radicals, if the bond scission is homogeneous, or a pair of positive and negative ions, if the bond scission is heterogeneous. The mechanochemical model for contact charging of materials states that these ions or the electrons released by the radicals are transferred between material surfaces when they are brought in contact with each other.

\subsubsection{Charging of Two Identical Materials Brought in Contact with Each Other [17]}

It has been observed that even when two surfaces of identical materials are contacted, charge transfer occurs between them causing one of the surfaces to be charged positively, and the other, negatively. The best way to ensure that the two materials are identical is to take a block and break it into two pieces. Even when this is done, charge transfer occurs between the two surfaces in contact. This fact, on account of the symmetry of the two surfaces, appears counterintuitive. 
Hence, all the mechanisms that have been put forth to explain this phenomenon try to suggest some way in which this symmetry might be broken.

Some models rely on the statistical variation in properties between the two surfaces to account for the charging.

Then there are those that depend on the presence of an external electric field. A material, when exposed to an electric field, becomes polarized, with one side acquiring a positive charge, and the other, a negative charge. Let us consider two identical objects being brought in contact with each other in the presence of an external electric field which is perpendicular to the surfaces in contact. Then, due to the polarization of the objects, we really have in contact two oppositely charged surfaces. Hence, charged species will be transferred between the oppositely charged surfaces, leading to the objects getting charged.

There is another model which has been put forth to explain this phenomenon for asymmetric contact between two identical surfaces. Such is the case when, for example, a small area of one surface is rubbed against a large area of another surface, as shown in fig. 3.8 below.
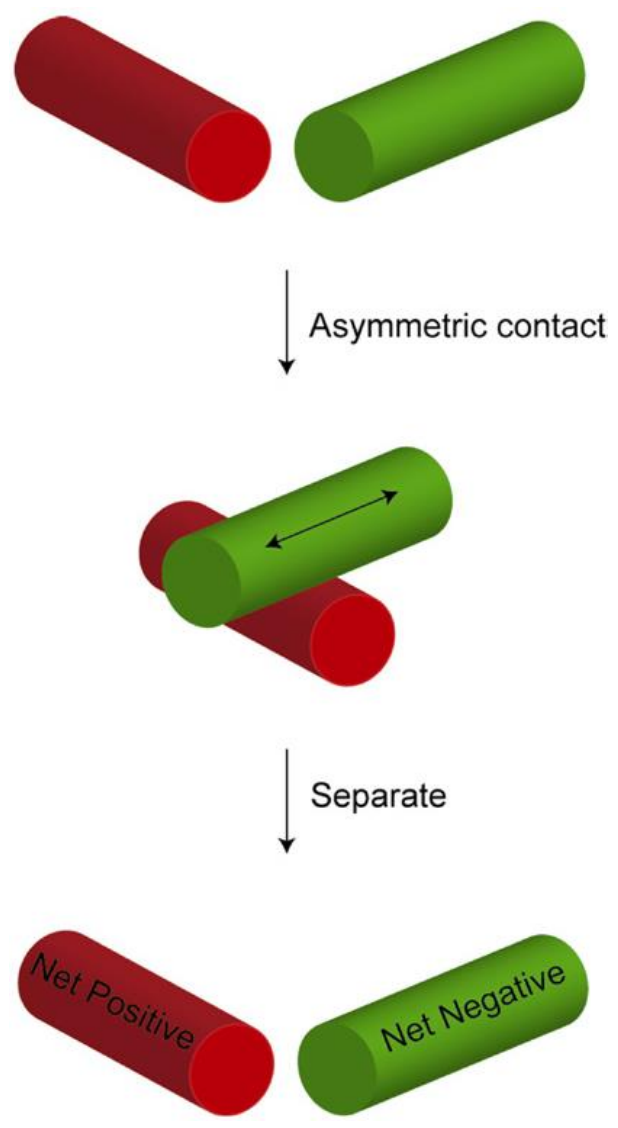

Fig. 3.8 Charging of Two Identical Materials Due To Asymmetric Contact (Reproduced from [17])

In this kind of contact, as depicted in fig. 3.8, usually the surface with the smaller contacting area acquires a net negative charge and that with the greater contacting area, a net positive charge. 
This is explained by a model due to Lowell and Truscott as shown schematically in the fig. 3.9 below.

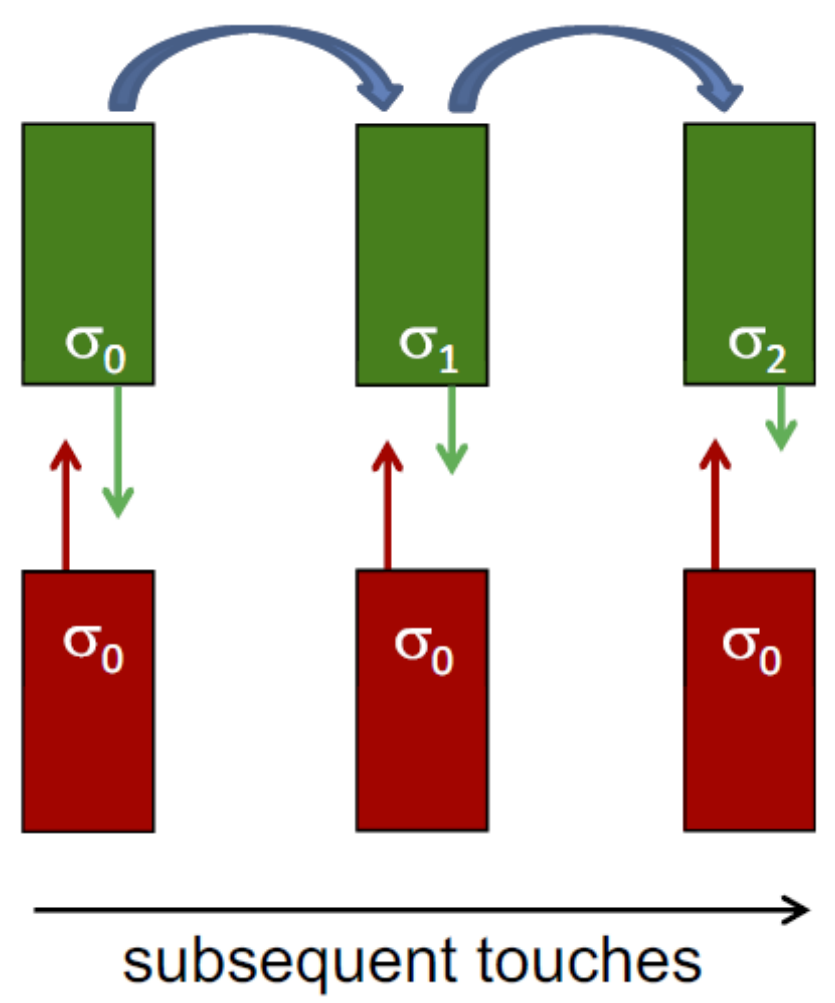

Fig. 3.9 The Lowell-Truscott Model for Charge Transfer between Two Identical Surfaces for Asymmetric Contact (Surface Density of Charged Species Trapped in High Energy States Represented by $\sigma$; No. of Species Transferred from Each Surface Represented by the Length of the Corresponding Arrow) (Reproduced from [17])

According to this model, when two surfaces are brought in contact with each other, charged species (generally, electrons or negative ions) are transferred from high-energy states of one surface to vacant low-energy states of the other. Hence, quite reasonably, the number of species transferred away from a given surface at each contact may be assumed to be proportional to the surface density, $\sigma$, of charged species trapped in high-energy states on that surface. Initially, as shown in fig. 3.9, the value of $\sigma$ is the same for both surfaces; it is denoted by $\sigma_{0}$. The same position of the green surface repeatedly touches the red surface. As a result, each contact causes this position to lose its trapped electrons. The value of $\sigma$ for this position reduces from $\sigma_{0}$ to $\sigma_{1}$ after the first contact, and from $\sigma_{1}$ to $\sigma_{2}$ after the second contact $\left(\sigma_{0}>\sigma_{1}>\sigma_{2}\right)$. However, different positions of the red surface are touched at each contact, and hence, the contacted positions always have the value $\sigma_{0}$ for $\sigma$ when the contact is made. Hence, in the second and the third touches, as depicted in fig. 3.9, greater number of charged species are transferred from the red surface to the green surface than in the reverse direction. Thus, the red surface acquires a net positive charge, and the green surface, a net negative charge. 


\subsubsection{Contact Charging of Granules [17]}

One interesting observation regarding the contact electrification of granules is that it appears to be particle-size dependent. In most cases, it has been observed that the smaller particles acquire a negative charge and the larger particles, a positive charge. The earliest indications of this occurrence were found from studies on such natural phenomena as dust devils and dust storms. The electric field developed in dust devils and dust storms has been found to be oriented perpendicular to ground, with the negative pole at a higher altitude. Now, smaller particles, on account of their smaller mass, are blown to higher altitudes. This observation suggests that the smaller particles are charged negatively and the larger particles, positively. Such has also been found to be the case for granules composed of a single material.

Attempts have been made to explain this behaviour by taking into account corrections necessary for the effective work functions of the materials and their capacitances considering their dependence on particle size. However, the magnitudes of these corrections have been found to be too low to account for the actual observations. Other efforts in this direction have taken into consideration the effect of particle-size on the adsorption of contaminants that alter the work function of a material and on the particle shape and surface roughness that affect the interparticle contact. These are also not considered suitable explanations on the ground that they make the charging highly system dependent, contrary to actual observations.

The contact charging of granules composed of a single material can be explained by all the mechanisms discussed in section 3.1.3. However, not all of them are capable of explaining the dependence of charging on the particle size. The mechanism based on the statistical variation of material properties explain the charging, but not its dependence on particle size. That based on the presence of an external electric field suggests that the charging of such granules should be dependent not only on the particle size, but also on the orientation of the field. The LowellTruscott model does explain the particle-size dependence of this charging as the smaller particles, having smaller number of charged species (generally, electrons or negative ions), are more likely to accept charged species than to donate them.

\subsection{Hazards Caused in the Industry Due To Charging of Solids}

Few have not felt the irksome shock from the metal handle when trying to open a door or a window in winter. This, though annoying, is bearable. Much more worrisome are the hazards that are caused in the industry due to solids getting charged by mutual contact. For, these not only lead to huge financial losses, but also turn fatal at times. In what follows, we shall talk about the various ways in charging of solids leads to hazards in industries dealing with particulate processes and the semiconductor industry. 


\subsubsection{Electrostatic Hazards in Particulate Processes [19, 20]}

Dust explosions occurring in the process industry is not new. Some of the gravest have taken place in the European foodstuff and the US grain industry (Bremen 1979, Metz 1981, USA 1976-1978). The German statistics, as of2003, shows that each day, at least one dust explosion occurs in Germany and every tenth explosion is caused due to static electricity.

For most particulate processes handling organic, or even metallic, products, the formation of an inflammable dust cloud is hardly avoidable. The contact of the product particles among themselves and with the walls of the equipment lead to build-up of charge on the product as well as on the equipment. If the charge build-up gets high enough to cause a discharge in the surrounding atmosphere, the inflammable dust cloud may be ignited by the hot plasma in the discharge channel.

A dust explosion may occur if fine particles of an inflammable material are dispersed in air. Particles having diameter more than $0.5 \mathrm{~mm}$ do not participate in the explosion. The finer the particles, the more sensitive the dust cloud to ignition sources and the more violent the ignition. Dust explosions, at atmospheric conditions, normally exhibit the following characteristics explosion range: from $20 \mathrm{~g} / \mathrm{m}^{3}$ to several $\mathrm{kg} / \mathrm{m}^{3}$; maximum explosion overpressure: 9 bar for organic materials up to $13 \mathrm{bar}$ for metal powder; maximum rate of pressure rise in a $1-\mathrm{m}^{3}$ vessel: 100-300 bar/s for organic materials to approximately $1000 \mathrm{bar} / \mathrm{s}$ for metal powder. So far as people are concerned, dust explosions, normally, are even more hazardous than gas explosions as the exposure to heat radiation lasts much longer in case of the former. The ignition sensitivity of a dust cloud is characterized, as done for any other fuel, by its minimum ignition energy (MIE). It may be noted that for a given material, the ignition energy turns out to be the lowest for very fine powder homogeneously dispersed to form a nearly quiescent cloud. The electrostatic discharges most frequently encountered in the industry have an energy which is normally less than $10 \mathrm{~mJ}$. Hence, the materials which have an MIE of $10 \mathrm{~mJ}$ or less are considered to be the most critical. But this is true only in the absence of inflammable gases or vapours. It must be borne in mind that the presence of inflammable gases or vapours leads to a ten-fold or greater reduction of the MIE for the resultant mixture, generally referred to as the 'hybrid mixture'. It may even happen that the MIE of the hybrid mixture goes down to the range of that of pure gases or vapours (typically $0.2-0.4 \mathrm{~mJ}$ for hydrocarbons).

Various forms of discharges, such as, spark, brush and propagating brush discharges, may lead to ignition hazards depending on the energy of the discharge and the MIE of the dust cloud. The occurrence of both spark and brush discharges may be eliminated by ensuring that the surface resistance lies below $10^{11} \Omega$ and above $10^{8} \Omega$. The surface resistance can be reduced and brought within the aforementioned limits by using antistatic additives. But there are two problems associated with this measure: the antistatic effect is often dependent on the relative humidity of the environment and the antistatic additives are sometimes absorbed by the product in contact with the treated surface. Propagating brush discharges can be eliminated by making 
use of conductive materials or insulating materials of low dielectric strength at all places which are potential seats for build-up of high surface charge densities. Brush discharges will not occur if the breakdown voltage across a non-conducting layer or sheet is less than $4 \mathrm{kV}$. Corona discharges are not considered incendive for dusts. Apart from the types of discharges mentioned above, there are two others, and they are typified by the fact that they can occur only in particulate processes. They are the cone discharge and the lightning-like discharge. These are discussed below.

The Cone Discharge: The first observation of such discharges was first made in 1979 by Maurer while silos were being filled with polyethylene granules. They appear as shown in fig. 3.10 below.

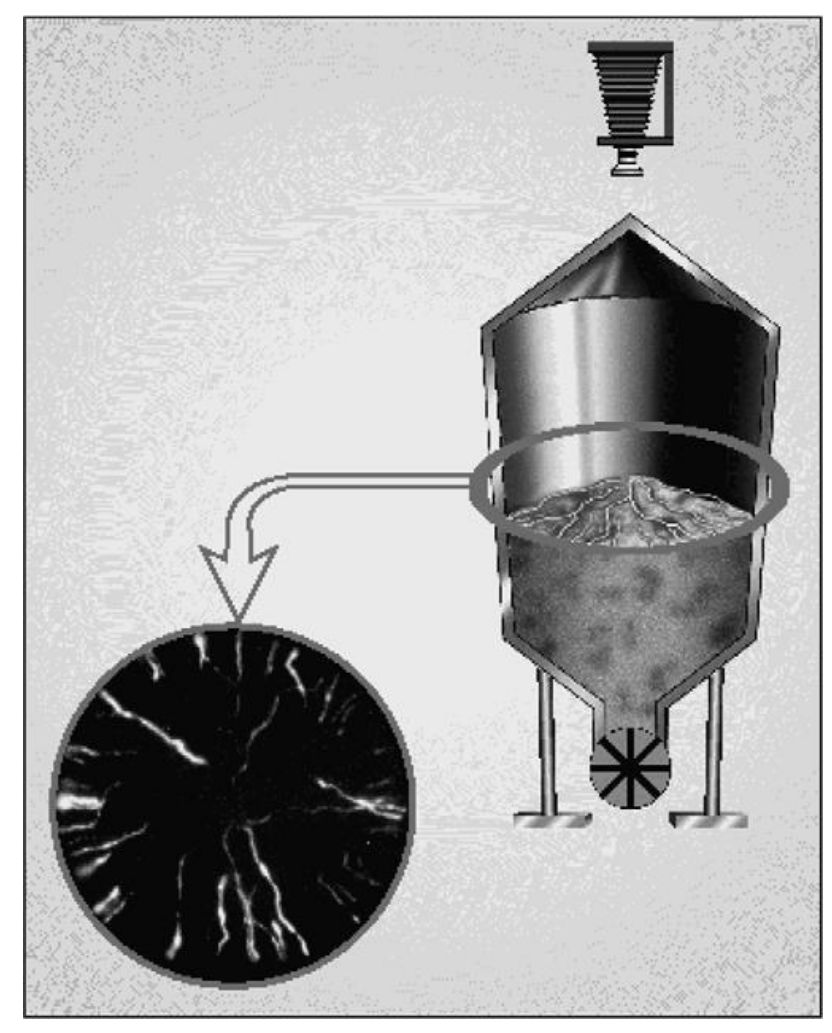

Fig. 3.10 Cone Discharge in a Silo (Reproduced from [20])

Cone discharges occur due to a phenomenon known as 'charge compaction'. When a product in powder form is fed into large containers or silos by a pneumatic transport system, and also by the action of gravity, the flowing powder gets dispersed in air. In this dispersed condition, the powder acquires charge by contact with the walls of the feed-pipe. This, depending on the specific charge and the degree of dispersion of the powder, may result in the development of high space charge densities in the conveying system. As the powdered product is dropped into the bed of the bulk material in the silo, along with mechanical compression and compaction of the particles, an extreme compaction of charge also takes place. If the product material has a low conductivity, the accumulated charge cannot easily dissipate to ground. Thus, a space charge 
density, that is much higher than that in the dust cloud in the pneumatic system, develops in the powder bed in the silo. This results in strong electric fields at the edges of the powder bed. The electric field intensity $E$, for a cylindrical bed, can be estimated by the formula

$$
E=\frac{\rho R}{2 \varepsilon_{r} \varepsilon_{0}} \ldots \text { (3.2) [20], }
$$

where $\rho$ is the space charge density in the bed, $R$ is the radius (in metres) of the cylindrical bed, $\varepsilon_{0}$ is the permittivity of free space $\left(\varepsilon_{0}=8.85 \times 10^{-12} \mathrm{~F} / \mathrm{m}\right)$ and $\varepsilon_{r}$ is the relative permittivity of the powder material.

This formula indicates that even a moderate specific charge of $10^{-7} \mathrm{C} / \mathrm{kg}$ in the powder in a silo just $1.5 \mathrm{~m}$ in diameter is sufficient to produce an electric field having intensity of the order of the dielectric strength of air. If a silo has a height greater than its radius, the produced electric field has, predominantly, a radial direction, its maximum value being at the inner wall of the silo. Along the path of least resistance, cone discharges occur in the form of discharge channels that point radially outwards if the bed has a height greater than the silo radius, as shown in fig. 3.10, or downwards through the bed if it has a height less than the silo radius. It has been observed that the incendivity of cone discharges increases with the silo diameter and the size of the particles in the bed of the bulk material.

It is presently held that if the resistivity of the bulk material is less than $10^{10} \Omega \mathrm{m}$, cone discharges are unlikely to occur. However, it is very difficult, in general, to increase the conductivity of bulk materials in industrial practice. In situations where exclusion of cone discharges appears to be a remote possibility and the equivalent energy of the discharge is anticipated to be greater than the MIE of the product to be handled, other means need to be resorted to. These include preventing the creation of potentially explosive mixtures by excluding inflammable gases, vapours and fine dust or by reducing the amount of oxygen in the mixture, and also designing the plant with explosion-protective elements.

The Lightning-like Discharge: Though this kind of discharge has not yet been observed in industrial silos and though its occurrence is considered highly improbable in such scenarios, it has not yet been completely ruled out conclusively. In fact, before the discovery of cone discharges, the charged dust cloud inside a silo was conceived to be the most dangerous as it was considered to be a potential source of lightning-like discharges. This hypothesis was based on the observation of lightning flashes in ash and dust clouds in erupting volcanoes. Experiments have shown that such discharges are not to be expected in silos with a volume of $60 \mathrm{~m}^{3}$ or with any other volume, but with a diameter not greater than $3 \mathrm{~m}$.

Further details on prevention of such hazards are provided in [12]. Adherence to such standards when designing process equipment for handling powders and dusts is of extreme importance. 


\subsubsection{Electrostatic Hazards in the Semiconductor Industry}

Static charge causes various problems to the semiconductor device industry. Problems, such as, particle contamination, damage and malfunctioning of equipment by electrostatic discharge (ESD) are the results of failure to control static charge. These as well as the remedies are discussed below.

The Problems [21, 22, 23]: Electrostatic attraction (ESA) increases particle contamination of critical product and equipment surfaces, causing defects and increasing maintenance costs. Modern cleanroom filtration keeps most external particles from entering the cleanroom. Particles are still produced inside the cleanroom by personnel, production equipment, and parts of the production process. Unfortunately, all of these particle sources are usually close to the product. If surfaces are charged, it attracts and holds particles that would otherwise remainairborne in the laminar airflow of the cleanroom. Sub-micron-sized particles cause defects in semiconductor production in much the same way that dust on a photographic negative or print paper causes a visual defect. Technological changes leading to miniaturization of semiconductor devices result in even very small particles turning out to be harmful. The smaller the particle, the easier it is to get it attached to a surface by electrostatic attractive forces and the more difficult it is to remove it from the surface.

Uncontrolled rapid transfer of static charge, often referred to as an electrostatic discharge (ESD), can damage a device by causing local heating, sufficient to melt the silicon or metallization of the semiconductor device. Other forms of damage that it can cause are filamentation, charge injection, oxide rupture and junction spiking. Moreover, ESD on a photomask (the "negative" used to produce the device) can cause melting damage, which produces a repeating defect each time the photomask is exposed, transferring the device patterns onto the silicon wafer.

The energy from ESD events also appear as signals in the radio-frequency spectrum. Being typically in the range of $100 \mathrm{MHz}$ to $2 \mathrm{GHz}$, these signals are in the same frequency range as the microprocessors that control the operations of most semiconductor production equipment. ESD events, thus, generate electromagnetic interference (EMI) that can cause a variety of equipment malfunctions ranging from simple stoppages to erratic robot operations that destroy products. As EMI propagates through both radiation and conduction, an ESD event in one piece of equipment may affect the operation of other equipment located nearby, thus, making the source of the problem difficult to locate.

Ways of Mitigation [22, 23, 24, 25]: It is suggested that semiconductor production environments make extensive use of grounding with conductive and static-dissipative materials so that charge on people, equipment and product can be controlled. For controlling charge on insulators, air-ionization techniques should be employed. It is recommended that everything be treated as static sensitive to be on the safe side. Something grounded should be touched before 
handling electronic assemblies or components. Grounded wrist-straps and shoe-straps should be worn by the personnel whenever possible. The relative humidity should be kept at $40 \%$ or greater. Leads, pins or traces should not be touched when handling devices as this can cause ESD. It is recommended that we not move around a lot since by moving around, the body may build up static charges. The personnel should refrain from touching electronic devices if they are getting static discharges. It is recommended that the static control recommendations of the International Technology Roadmap for Semiconductors (ITRS) and the standards issued by Semiconductor Equipment and Materials International (SEMI) and the ESD Association (ESDA) be adhered to. Both the ITRS and the SEMI recommend that electrostatic issues be taken care of while building a factory and installing the equipment rather than waiting until an actual electrostatic problem occurs during production as that may turn out to be very costly.

The materials of which containers of electronic devices are made should also satisfy certain criteria to ensure protection of the devices from ESD. The packing materials in proximity to the devices should not be static generative and the entire intermediate container should form a Faraday shield to protect all the enclosed devices from external static voltages. The inner surfaces of the containers should be static dissipative, i.e., their surface resistivity should lie between $1 \times 10^{5} \Omega$ /square and $1 \times 10^{12} \Omega$ /square. The conductive coating may have a maximum surface resistivity of $1 \times 10^{4} \Omega /$ square. Tests like the static voltage test should be conducted to assess the suitability of such materials. Other testing methods also exist, such as, the peeling test and the unrolling test, that are conducted for the tape-and-reel container. (The tape-and-reel is a type of container used to package semiconductor devices. Other such containers are the stick magazine and the matrix tray.)

The circuits in the devices should also be improved by designing elements that are able to handle the ESD currents in a better way and by providing an alternate path (a shunt) for the charge to travel as it passes through the part. The shunt protects the sensitive elements in the device by clamping the voltage developed during the ESD event and diverting the current away from the core circuit. 


\section{Chapter 4}

\section{Principles of Fire}

We have seen the various ways in which the electrostatic charging of liquids and solids can give rise to ignition hazards and ways of mitigating them. But, a few questions still remains unanswered. Is it that the simultaneous presence of fuel, oxygen and an ignition source at a place must always lead to a fire? Supposing that a fire occurs, how long will it sustain and how far will it spread? It is the answers to these questions and similar others that we shall now try to find out. The discussion presented here is based on the details available in [11]. We shall start by looking at the principles of the combustion reaction.

\subsection{Combustion}

Combustion is an exothermic reaction that involves a fuel in the condensed-phase or gas-phase or both and is self-sustaining in nature. It is usually, though not necessarily, connected with oxidation of a fuel by oxygen present in air and also with emission of light. In condensed-phase fuels, combustion generally gives rise to a glow. But flames are observed in gas-phase combustion processes. If the process in confined and this leads to a rapid increase of pressure, then it is referred to as an explosion.

\subsection{Ignition: Piloted Ignition and Autoignition}

The process of initiating a self-sustained combustion reaction is known as ignition. If this is caused by an external agent, such as, a small external flame, a spark or a glowing object, the process is referred to as piloted ignition. But, if the assistance of an external source is not needed for the ignition to occur, then it is called autoignition.

For the fuel and oxygen molecules to be able to react chemically and produce heat, they must first be excited to some activated state. This excitation may be done by other excited molecules in a nearby flame or spark. It may also be achieved by raising the temperature of the fuel/oxygen mixture. The excited fuel and oxygen molecules interact to produce heat as well as other excited molecules. If sufficient fuel and oxygen are present, as also sufficient number of activated molecules, ignition occurs as a chain reaction in which activated species are produced faster than they are naturally decayed. Once ignition has been initiated, it will continue to occur until all the available fuel and oxygen has been consumed, or until the flame has been 
extinguished, say, by cooling or by reducing the number of excited molecules or in some other way.

Initiation of the flame occurs, in case of most combustible solids and liquids, in their gaseous phase. Exceptions are pure carbon, certain metals and certain other substances in which direct solid-surface oxidation takes place leading to smouldering. For most solids and liquids, sufficient thermal energy first needs to be supplied to convert a part of the fuel to its vapour, so that a combustible gaseous-phase mixture may be produced. In such cases, a minimum temperature can be identified, at which a combustible mixture may be formed near the fuel surface. This temperature is called the piloted ignition temperature since a pilot is needed to initiate the ignition of the gas mixture. For flammable liquids, it is known as the flashpoint.

Higher the temperature of the fuel/air mixture, lesser is the pilot energy required to ignite the mixture. At a sufficiently high temperature, the mixture ignites spontaneously, i.e., without the need for a pilot. This temperature is called the autoignition temperature.

In general, ignition temperatures of gas mixtures depend on various factors like the composition of the mixture, ambient pressure, volume and shape of the vessel in which the ignition is carried out, and also the nature and energy of the pilot. Hence, different ignition temperatures are sometimes reported for the same substance because of difference in the testing methods used.

\subsection{The Limits of Flammability}

A flame, initiated in a fuel/oxidant mixture, will continue to propagate if and only if the concentration of the fuel in the oxidant is within a specified range for a given temperature and pressure. For example, for hydrogen/air mixtures, an initiated flame will continue propagation if the concentration of hydrogen in air lies between $4 \%$ and $74 \%$ by volume at $21{ }^{\circ} \mathrm{C}$ and atmospheric pressure. The smaller and the larger values of fuel concentration are respectively known as the lower flammability limit (LFL) and the upper flammability limit (UFL). They are also called respectively the lean and the rich limits of flammability. The flammability range widens if the temperature of the mixture is increased; the range narrows if the temperature is decreased. A flammable mixture may be caused to become non-flammable by a decrease of temperature due to reduction of the fuel's range of flammability. These facts are depicted in the following figure (fig. 4.1). 


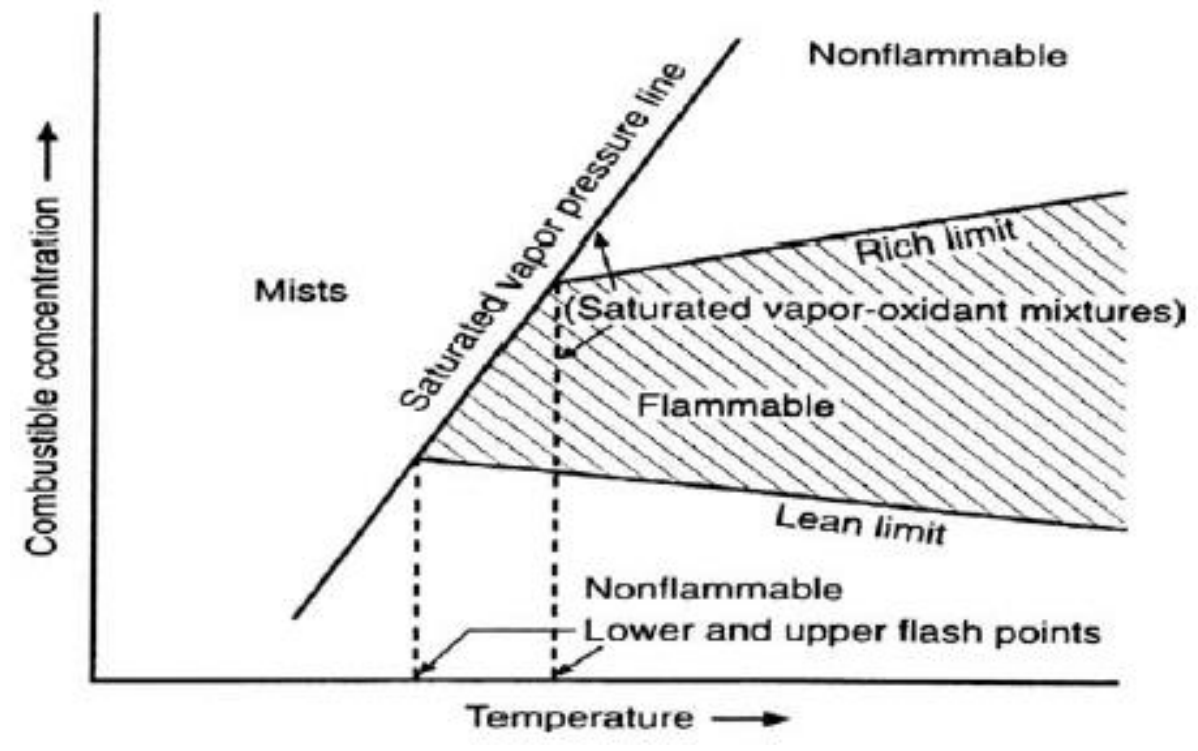

Fig. 4.1 Flammability Limits and Flash Points (reproduced from [11])

As can be observed in fig. 4.1, in case of liquid fuels in equilibrium with their vapours in air, there exists a minimum temperature for each fuel above which sufficient vapour is formed to give rise to a flammable mixture. A maximum temperature also exists above which the concentration of fuel vapour is too high to be able to propagate flame. The minimum and maximum temperatures are respectively known as the lower and the upper flash points in air. For temperatures below the lower flash point, fuel vapour is not present in sufficient quantity to sustain ignition. The flash point temperatures for combustible liquids increase with increase in atmospheric pressure.

\subsection{Fire Point}

The lowest temperature at which a liquid gives off vapours fast enough to be able to support continuous combustion is called the fire point of the liquid. Usually, the fire point is at a few degrees higher than the lower flash point. For typical fuels, vaporization needs to occur at a rate of at least $4 \mathrm{~g} / \mathrm{m}^{2} \mathrm{sec}$ to support continuous combustion.

It should be borne in mind that it is possible for fire to spread even over a liquid whose temperature is well below its lower flash point, provided that a source ignition has been established. In such situations, the liquid surface gets locally heated by the ignition source or fire so that the temperature of the liquid rises above its fire point. 


\subsection{Principles of Fire}

Fires, unlike explosions, take place in situations where the fuel and the oxidant are initially unmixed. Explosions, on the other hand, occur in situations where an intimate mixture of fuel and oxidant is available. Hence, for explosions, the combustion reaction proceeds very fast since the delay caused in fires for bringing together the fuel and the oxidant is avoided. In fires, the burning rates are determined mainly by the supply of fuel and oxidant (air) to the flames rather than the rates of the basic chemical reactions that occur within the flames. These chemical reactions occur so fast that all the fuel and oxidant that is supplied to the flames get consumed almost immediately. In fires, the combustion reaction occurs along thin flame sheets, known as "diffusion flames", which separate regions that are rich in fuel vapour from those rich in oxidant. Fuel vapour and oxidant diffuse towards the flame sheet, where they react producing the combustion products and heat, which, in turn, diffuse away from the flame sheet.

Small diffusion flames, such as, that from a burning matchstick or candle, appear quite smooth and steady. They are termed "laminar" diffusion flames. If the fire is allowed to grow, the flames gradually become more and more unstable and they wiggle around, searching for more fuel or oxidant. Eventually, the motion of the flames becomes truly random, and such flames are termed "turbulent" diffusion flames.

In case of laminar diffusion flames, burning rates are governed by the convective transfer of heat from the flame to the solid fuel. Due to this convective heat transfer, the solid fuel gets heated up and gasifies, and thus, it supplies fuel vapours to the flames. The hot combustion products move upwards due to buoyancy and this creates a partial vacuum in their original position. The air from below rush to fill up the "gap" and this is how, oxidant gets supplied to the fuel. This buoyant flow may also help in increasing the convective transfer of heat from the flames to that part of the fuel that has not yet been involved in the combustion process. It is this transfer of heat from the flame to the as yet uninvolved fuel which determines the rate of spreading of a flame.

In case of larger fires that involve turbulent diffusion flames, heat transfer from the flame to the fuel is caused dominantly by radiation. It has often been observed that fuels that are considered to be relatively less flammable for laminar flames turn out to be highly flammable in case of fires involving turbulent flames because of this enhanced role of flame radiation. 


\section{Chapter 5}

\section{Gaps in Knowledge and Ways of Bridging Those}

\subsection{Knowledge Gap in Electrostatics of Liquids and Way of Bridging It}

The Issue: The use insulating plastic pipes in fuel handling is widespread today. As has been pointed out in section 2.2.2, such pipes are quite likely to present us with hazardous scenarios unless extreme precautions are taken. Hence, it is important to analyze the suitability of such pipes for such purposes in terms of safety.

What has been done: Walmsley perused details of reported fire incidents at petrol stations that used such pipes, available data on voltage measurements and spread of streaming currents in gasoline handling as also the theoretical estimates of the voltages developed on non-conductive pipes, and concluded that the voltages on insulating surfaces could occasionally exceed the threshold for hazardous brush discharge from insulating surfaces [26].

However, from experiments conducted in a full-scale high density polyethylene (HDPE) pipe-work system, it has been concluded that use of such means is safe for all practical purposes $[27,28]$. The tests were conducted by passing highly charging fuels, isooctane-toluene mixture and white spirit, through a full-scale pipeline like those which are used in filling stations. The potentials developed on the surface of pipe wall, the electrofusion couplers and valves were monitored. These measurements showed that electric fields high enough to result in a breakdown of the pipe wall were never produced. Moreover, the potentials on the surface of the pipe never reached levels that could result in brush discharges energetic enough to ignite the fuel vapours. However, it has been recommended that for electrofusion couplers, either grounding or use of sealing caps for prevention of electrostatic discharge is necessary. It has finally been concluded that such insulating pipe-work is safe for fuel handling if the relevant standard (EN 14125:2004) is followed [27].

What remains to be done: The above discussion clearly indicates that there is confusion regarding the safety of using insulating plastic pipes in fuel handling. An experimental study may be undertaken to clarify this confusion.

What may be done to bridge the knowledge gap: Various liquid fuels available in the market may be allowed to flow through an HDPE pipe, preferably through a full-scale pipeline, and in each case, the voltage developed on the surface of the pipe, the electrofusion couplers and valves, and also the streaming current developed may be measured. The measurements should be taken for different fuel-flow velocities as the streaming current produced depends on the velocity 
of the flowing liquid. This will help us to get an estimate of the range of fuel-flow velocities that may be considered safe for use.

The test rig to be used may be similar to the one used in [27], the schematic diagram of which is shown below (fig. 5.1).

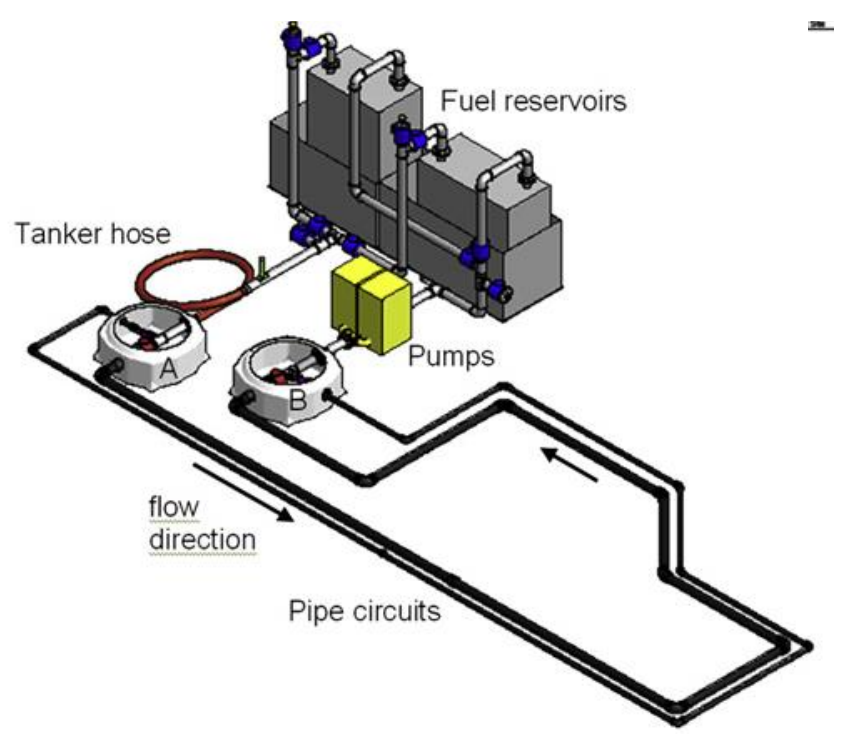

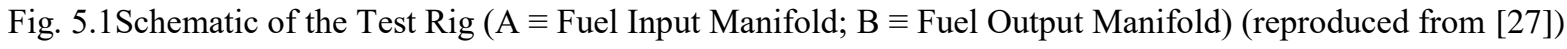

The JCI 140 electrostatic fieldmeter may be used to monitor the potential on the pipe surface. The potentials developed on the electrofusion coupler coils may be monitored using the JCI 148 electrostatic voltmeter.

\subsection{Knowledge Gaps in Electrostatics of Solids and Ways of Bridging Those}

\subsubsection{Regarding the Contact Charging of Insulators}

The Issue: The mechanism of contact charging of solids when at least one of them is an insulator in not clear. Various mechanisms have been proposed; these have been discussed in sections 3.1.2 - 3.1.4. However, an understanding of the phenomenon still remains hazy. This calls for an investigation into the nature of charge produced on the surface of an insulator when subjected to contact charging or tribocharging.

What has been done: It has been observed that when an insulator surface is contacted with a metal or by another polymer, the polymer develops on its surface arrays of both positive and negative charge, the net charge on the surface being either positive or negative. The magnitude of the local charge may be greater than the net charge which represents a loose balance of the contributions from the positive and the negative regions. Terris et al, in [29], have shown using atomic force microscopy that the patterns of charge developed on a polymer on contact with a 
narrow metal tip ( $10 \mu \mathrm{m}$ diameter) have had regions of both positive and negative charge, with domain sizes on the order of several micrometres. Baytekin et al have shown in [30] using Kelvin force microscopy that two polymer surfaces, on being brought in contact with each other, have developed on their surfaces, intricate 'mosaics' of positively and negatively charged regions. Albrecht et al have used atomic force microscopic as well as electric force imaging mode techniques to study the tribocharging of polymers [31]. They have observed bipolar exchange of charge between the samples involved. They have also noticed that oppositely charged domains could be stable side by side. Similar observations have been made by Pham et al in [32] for the case of contact charging of two identical insulators.

What remains to be done: It is of interest to find out whether similar patterns of charge are also developed on an insulator surface when subjected to corona charging and induction charging.

What may be done to bridge the knowledge gap: Samples of polymers, such as, LDPE, PTFE, nylon, PDMS etc., may be subjected to corona and induction charging, and the charge patterns developed on the surface may be observed using Kelvin Force Microscopy. For corona charging, experiments may be conducted using both positive and negative corona. The net charge developed on a sample may be Faraday cup connected to an electrometer (Keithley, 6517B).

\subsubsection{Regarding the Surface Potential Decay of Polymers}

The Issue: The study of surface potential decay characteristics of polymers is important as it helps us to get insight into the effectiveness of some important technological processes. As an example, such studies help us to understand the long-term performance of electrets [33], which are used in various applications, such as, the microphone.

What has been done: It has been shown in [34] that the relative humidity has a large effect on the electric potential decay of polyethylene. It has also been shown that positive potential decays faster than negative potential. The experiment constituted corona-charging a few appropriately processed LDPE samples and subjecting them to electrostatic potential measurements as well as Kelvin Force probe Microscopic (KFM) and Electric Force Microscopic (EFM) measurements. The influence of atmospheric humidity on the charging and discharging of insulating solids have also been demonstrated in [35-38].For example, it has been observed that glass beads in a fluidized bed exhibit intense charging below a relative humidity of $40 \%$, but show no charging above this value of relative humidity [35]. For particulate aluminium hydroxide, it has been observed that the stationary charge acquired by it under pneumatic flow is lower at higher humidity [36]. The surface conductivity of dielectrics has also been shown to increase with atmospheric humidity, and this has been attributed to absorbed water [39, 40].

That the atmospheric pressure too has an influence on the surface charge of polymers subjected to tribocharging and corona charging has been demonstrated by Hogue et al [41-43].It 
has been shown that polymers charged triboelectrically or by corona lose the charge with a rapidity that increases with decreasing atmospheric pressure. For induction charging, the surface charge has been shown to be relatively insensitive to ambient pressure [43].

The effect of temperature on the charging of insulators has been demonstrated in [36] and [38]. In [36], it has been shown that the charge acquired by aluminium hydroxide during pneumatic transport increases with temperature (from $19^{\circ} \mathrm{C}$ to $30^{\circ} \mathrm{C}$ ) for a higher value of suspension density $\left(50 \mathrm{mg} / \mathrm{m}^{3}\right)$. The charging has been found to be relatively less dependent on temperature for the lower value of suspension density $\left(10 \mathrm{mg} / \mathrm{m}^{3}\right)$. In [38], it has been shown for a corona-charged thin film of polyethylene terephthalate (PET) that the time required for the surface potential to decay to $50 \%$ of its initial value has been dependent more on temperature and less on relative humidity, while that required for this charge to decay to $10 \%$ of its initial value has been determined more by relative humidity and less by temperature.

The effects of exposure of polyethylene to gamma irradiation and the irradiation environment on the surface-potential decay of polyethylene have been investigated in [33]. To investigate the effect of the irradiation environment, the irradiation was carried out in air, nitrogen gas and vacuum. Both the above factors have been found to have a significant effect. Exposure to gamma irradiation had the effect of decreasing the rate of decay of surface-potential. This has been conceived to be indicative of the fact that the charge stability of electrets might be improved by gamma irradiation.

What remains to be done: However, various aspects of this phenomenon still need to be investigated. It is not known how the surface charge decay of a polymer depends on pressure higher than atmospheric. How the presence of different gases might influence this decay is also unknown.

For gamma-irradiated polyethylene, the influence of temperature and pressure on surface charge decay needs to be investigated. In [33], the study on gamma-irradiated polyethylene has been carried out using negative corona. It is not known what could happen if positive corona is used. The effects of such factors on surface charge decay are yet to be explored for other polymers, such as, polyethylene naphthalate, polyethylene terephthalate, PTFE.

What may be done to bridge the knowledge gap: The experiment needs to be conducted in a closed chamber with an inlet and an outlet for allowing the entry and the exit of a gas. The chosen gas may be pumped into the chamber until the desired pressure is achieved. If this gas needs to be replaced by a different gas, the chamber should first be evacuated before the new gas is pumped in. The humidity inside the chamber may be controlled by controlling the flows of two merging current of the gas - one dry and the other water-saturated which is produced by bubbling it through distilled water, as has been described in [34]. The arrangement could be as shown below (fig. 5.2). 


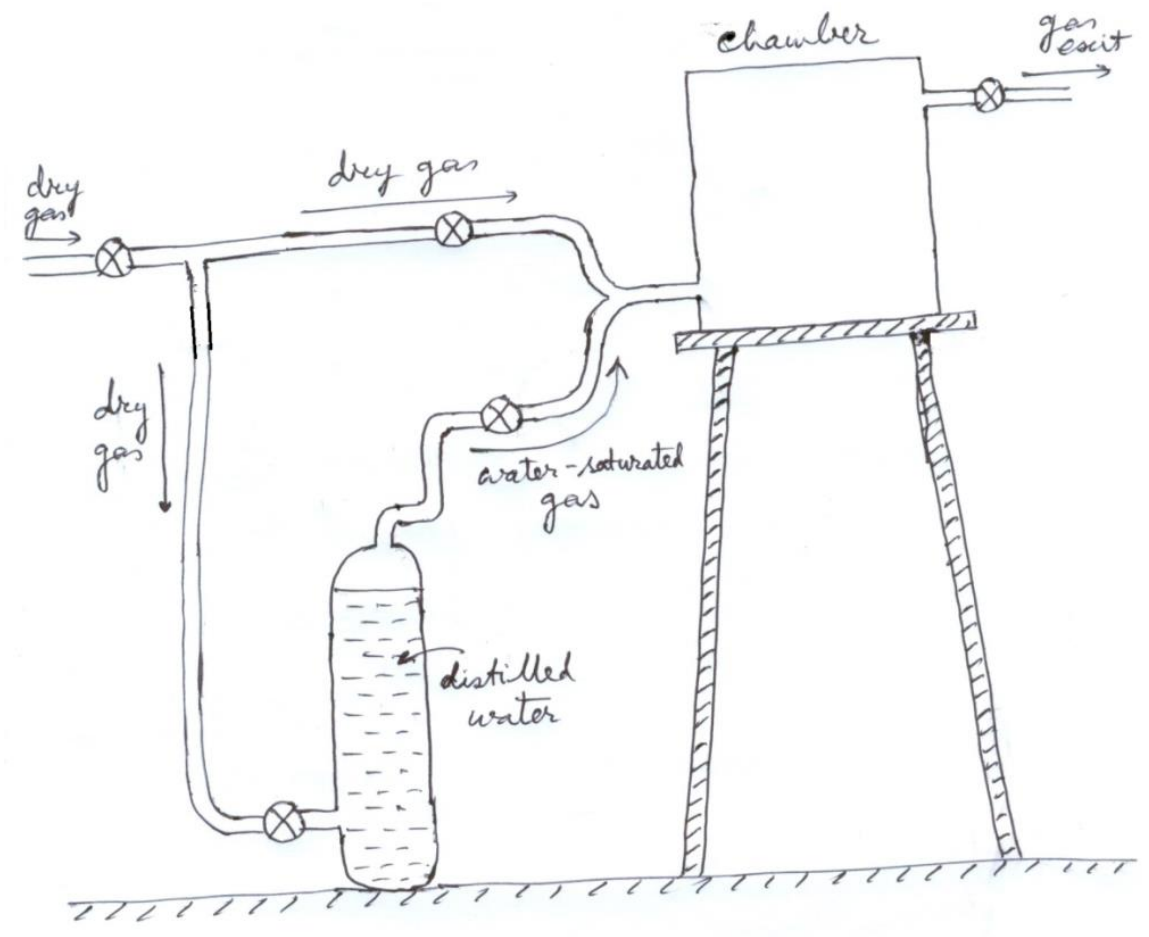

Fig. 5.2 Arrangement for Controlling Humidity inside the Chamber

The pressure inside the chamber may be monitored using a pressure gauge which can measure pressure above atmospheric, such as, Omega DPG5500B-30A. The temperature and the humidity inside the chamber may be measured using a digital thermohygrometer (Minipa MTH-1380 or ETI 6102). Immediately after charging, the sample should be placed near a static monitor (JCI 140) so that the potential on the charged surface may be monitored. The possible setup for this could be as follows (shown for negative corona charging in fig. 5.3).

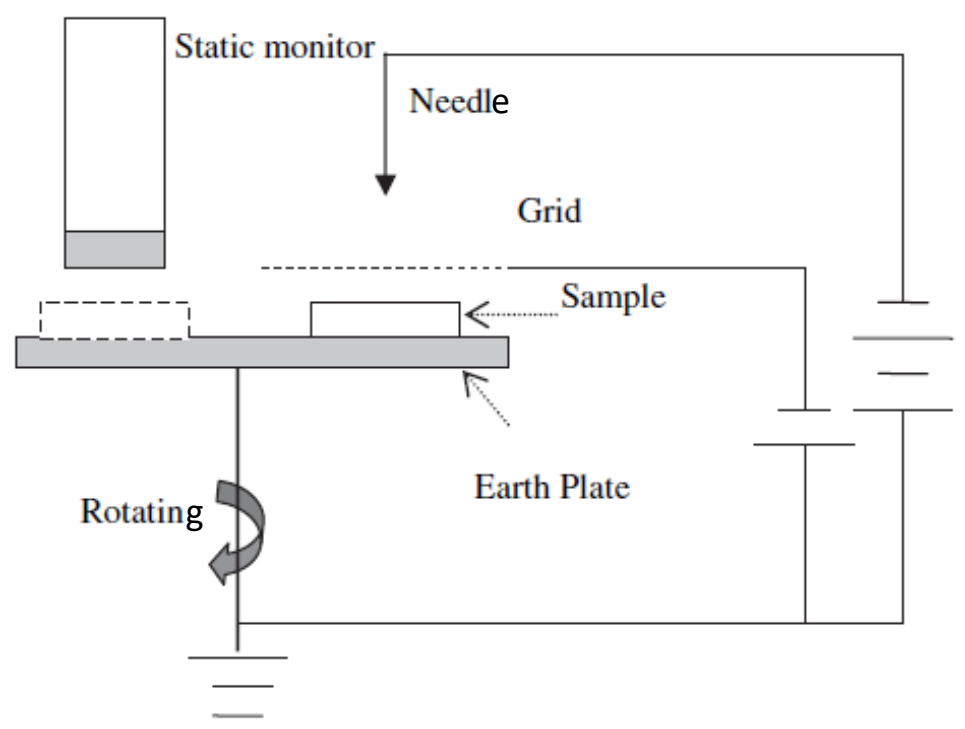

Fig. 5.3 Setup for Negative Corona Charging and Potential Decay Measurement (Reproduced from [33]) 
Using the setup shown in fig. 5.3, the sample, after being charged, may be immediately rotated to the position below the static monitor. For positive corona charging, the polarities of the needle and the grid need to be reversed. For induction charging, the needle should be replaced by a metal plate. The grid should be removed and the metal plate should be connected to a variable power supply. For tribocharging, the needle should be replaced by a plate to which a woollen pad (or a pad of any other suitable material) may be attached. Use may be made of a small DC motor, which should be connected to the plate, for rubbing the pad against the sample. The grid should obviously be removed.

\subsubsection{Regarding the Tribocharging of Wood}

The Issue: Sawdust is produced in manufacturing operations that involve cutting and sanding of wood. It has been observed that transport of this sawdust through pneumatic systems leads to generation of charge $[44,45]$. In a typical triboelectric series, wood is placed around the middle of the table [44, 45]. PTFE, the material used in the pneumatic systems mentioned above, being placed below wood in the triboelectric series, must charge negatively when rubbed with wood (as discussed in section 3.1.2). Further details need to be obtained about the charging that occurs when sawdust of different species of wood is transported through pneumatic systems.

What has been done: In [44], [45] and [46], the author has described investigations on the tribocharging of different varieties of wood with PTFE. The experiments constitute rolling a ball on a plank, made of PTFE and wood, respectively, and vice-versa, and measuring the charge on the sphere by an electrometer.

What remains to be done: This, however, does not depict the scenario of saw-dust being transferred through PTFE pipes. This is because in that case, interaction among the saw-dust particles themselves also contributes to the charge generation process.

What may be done to bridge the knowledge gap: This gap may be bridged in the following way. A PTFE cylinder may be filled with saw-dust, shaken vigorously and the charge generated in the saw-dust and the cylinder measured. This may be done using the following setup (fig. 5.4). 


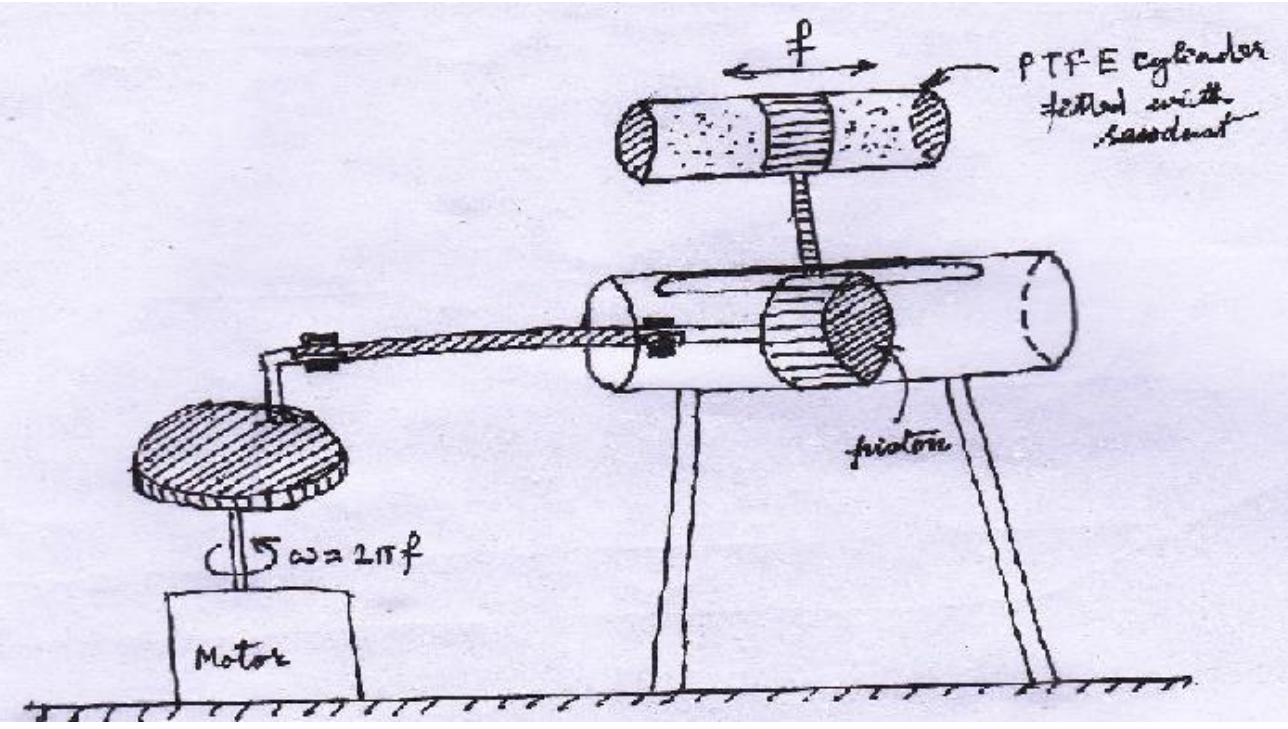

Fig. 5.4 Setup for Shaking the Cylinder Filled with Sawdust at a Particular Frequency

The charge developed in the sawdust may be measured by pouring it into a Faraday cup connected to an electrometer (Keithley, 6517B). 


\section{References}

1. U. von Pidoll, H. Kramer and H. Bothe, "Avoidance of Electrostatic Hazards during Refueling of Motorcars", Journal of Electrostatics, Vol. 40 \& 41, June 1997, pp. 524-528.

2. US Chemical Safety and Hazard Investigation Board, "Barton Solvents: Static Spark Ignites Explosion inside Flammable Liquid Storage Tank”, Case Study No. 2007-06-IKS.

3. M.Glor, "Ignition source static electricity: Incident investigation", Journal of Electrostatics, Volume 67, Issues 2 \& 3, May 2009, pp. 242-246.

4. H. S. Taylor and S. Glasstone, "A Treatise on Physical Chemistry, Vol. 2: States of Matter", D. Van Nostrand Company, Inc., 1952.

5. S. Glasstone, "Textbook of Physical Chemistry", Macmillan, 1952.

6. A. W. Bright, R. P. Corbett and J. F. Hughes, "Engineering Design Guides 30: Electrostatics", Oxford University Press, 1978.

7. T. H. Pratt, "Electrostatic Ignitions of Fires and Explosions", Centre for Chemical Process Safety of the American Institute of Chemical Engineers, 2000.

8. L. B. Loeb, "Static Electrification", Springer-Verlag, 1958.

9. K. Campden, "Electrostatics: Fields of Interest", IEEE Review, October 1991, pp. 335338.

10. Journal of Electrostatics, Vol. 27, Issues 1 \& 2, 1992.

11. "Fire Protection Handbook", National Fire Protection Association, September 1981.

12. IEC/TS 60079-32-1 and IEC 60079-32-2.

13. A. J. Dekker, "Solid State Physics", Macmillan, 1971.

14. F. A. Vick, “Theory of Contact Electrification”, Static Electrification, Supplement No. 2, British Journal of Applied Physics, The Institute of Physics, London, 1953, pp. S1-S5.

15. S. Matsusaka, H. Maruyama, T. Matsuyama, M. Ghadiri, "Triboelectric Charging of Powders: A Review”, Chemical Engineering Science, Vol. 65, 2010, pp. 5781-5807

16. W. R. Harper, "The Volta Effect as a Cause of Static Electrification", Proceedings of the Royal Society, London, A, 1951, pp. 83-103

17. D. J. Lacks and R. M. Sankaran, "Contact Electrification of Insulating Materials", Journal of Physics D: Applied Physics44, 2011, pp. 1-15.

18. M. W. Williams, "Triboelectric Charging of Insulating Polymers - Some New Perspectives", AIP Advances 2, 2012, pp. 010701-1 to 010701-9.

19. M. Glor, "Hazards Due to Electrostatic Charging of Powders", Journal of Electrostatics, Vol. 16, Issues 2-3, 1985, pp. 175-191.

20. M. Glor, "Ignition Hazard Due to Static Electricity in Particulate Processes", Journal of Electrostatics, Vol. 135-136, 2003, pp. 223-233.

21. J. E. Vinson and J. J. Liou, "Electrostatic Discharge in Semiconductor Devices: An Overview", Proceedings of the IEEE, Vol. 86, No. 2, February 1998, pp. 399-418. 
22. J. E. Vinson and J. J. Liou, "Electrostatic Discharge in Semiconductor Devices: Protection Techniques", Proceedings of the IEEE, Vol. 88, No. 12, December 2000, pp. 1878-1900.

23. A. J. Steinman, "Preventing Electrostatic Problems in Semiconductor Manufacturing", Compliance Engineering, Annual Reference Guide, 2004.

24. C. Troxtell and J. Huckabee, "Electrostatic Discharge (ESD) Protective Semiconductor Packing Materials and Configurations", Application Report SZZA027A - April 2002, Texas Instruments.

25. M. N. O. Sadiku and C. M. Akujoubi, "Electrostatic Discharge (ESD)", IEEE Potentials, Vol. 22, Issue 5, Dec. 2003 - Jan. 2004, pp. 39-41.

26. H. L. Walmsley, "Electrostatic Ignition Hazards with Plastic Pipes at Petrol Stations", Journal of Loss Prevention in the Process Industry, Vol. 25, Issue 2, March, 2012, pp. $263-273$.

27. G. L. Hearn, U. von Pidoll, J. M. Smallwood and A. Ticci, "An Assessment of Electrostatic Ignition Hazards Associated with Fuel Flow through Plastic Pipes at Roadside Filling Stations", Journal of Electrostatics, Vol. 70, 2012, pp. 179-183.

28. G. L. Hearn, "Electrostatic Ignition Hazards Arising from Fuel Flow in Plastic Pipelines", Journal of Loss Prevention in the Process Industry, Vol. 15, Issue 2, March, 2002, pp. $105-109$.

29. B. D. Terris, J. E. Stern, D. Rugar and H. J. Mamin, "Contact Electrification using Force Microscopy", Physical Review Letters, Vol. 64, No. 24, December 1989, pp. 2669-2672.

30. H. T. Baytekin, A. Z. Patashinski, M. Branicki, B. Baytekin, S. Soh, B. A. Grzybowski, "The Mosaic of Surface Charge in Contact Electrification", Science, Vol. 333, July 2011, pp. 308-312.

31. V. Albrecht, A. Janke, E. Nmeth, S. Spanje, G. Schubert and F. Simon, "Some aspects of polymers' electrostatic charging effects", Journal of Electrostatics, Vol. 67, Issue 1, 2009, pp. 7-11.

32. R. Pham, R. Craig Virnelson, R. M. Sankaran, D. J. Lacks, "Contact Charging between Surfaces of Identical Insulating Materials in Asymmetric Geometries", Journal of Electrostatics, Vol. 69, Issue 5, October 2011, pp. 456-460.

33. G. Chen, "Influence of gamma irradiation on surface potential decay of corona charged polyethylene", Journal of Electrostatics, Vol. 68, Issue 6, December 2010, pp. 487-491.

34. T. A. de Lima Burgo, C. A. Rezende, S. Bertazzo, A. Galembeck and F. Galembeck, "Electric potential decay on polyethylene: Role of atmospheric water on electric charge build-up and dissipation", Journal of Electrostatics, Vol. 69, 2011, pp. 401-409.

35. J. Guardiola, V. Rojo and G. Ramos, "Influence of particle size, fluidization velocity and relative humidity on fluidized bed electrostatics", Journal of Electrostatics, Vol. 37, Issue 1-2, May 1996, pp. 1-20.

36. S.R. Woodhead and D.I. Armour-Chelu, "The influence of humidity, temperature and other variables on the electric charging characteristics of particulate aluminium hydroxide in gas-solid pipeline flows", Journal of Electrostatics, Vol. 58, Issue 3-4, June 2003, pp. 171-183. 
37. K. Das-Gupta and W.F. Schmidt, "Electrical properties of surfaces of unirradiated and irradiated polymers in humid environments", IEEE Transactions on Components Packaging and Manufacturing, Part A, Vol. 18, No. 2, June 1995, pp. 266-269.

38. L. Herous, M. Nemamcha, M. Remadnia and L. Dascalescu, "Factors that influence the surface potential decay on a thin film of polyethylene terephthalate (PET)", Journal of Electrostatics, Vol. 67, Issue 2-3, May 2009, pp. 198-202.

39. R.S. Blacker and A.W. Birley, "Electrostatic charge occurrence, significance and measurement", Polymer Testing, Vol. 10, Issue 4, 1991, pp. 241-262.

40. R.F. Field, "The formation of ionized water films on dielectrics under conditions of high humidity", Journal of Applied Physics, Vol. 17, Issue 5, 1946, pp. 318-325.

41. M.D. Hogue, C.R. Buhler, C.I. Calle, T. Matsuyama, W. Luo and E.E. Groop, "Insulatorinsulator contact charging and its relationship to atmospheric pressure", Journal of Electrostatics, Vol. 61, Issue 3-4, July 2004, pp. 259-268.

42. M.D. Hogue, E.R. Mucciolo, C.I. Calle and C.R. Buhler, "Two-phase equilibrium model of insulator-insulator contact charging with electrostatic potential", Journal of Electrostatics, Vol. 63, Issue 3-4, March 2005, pp. 179-188.

43. M.D. Hogue, E.R. Mucciolo and C.I. Calle, "Triboelectric, corona, and induction charging of insulators as a function of pressure", Journal of Electrostatics, Vol. 65, Issue 4, April 2007, pp. 274-279.

44. W. D. Greason, "Triboelectrification of Wood", $46^{\text {th }}$ IEEE Industry Applications Society Annual Meeting, October 2011, pp. 1-5.

45. W. D. Greason, "Triboelectrification of Wood", IEEE Transactions on Industry Applications, Vol. 48, Issue 4, July/August 2012, pp. 1177-1181.

46. W. D. Greason, “Triboelectrification of wood with PTFE”, Journal of Electrostatics, Vol. 71, Issue 2, April 2013, pp. 140-144. 